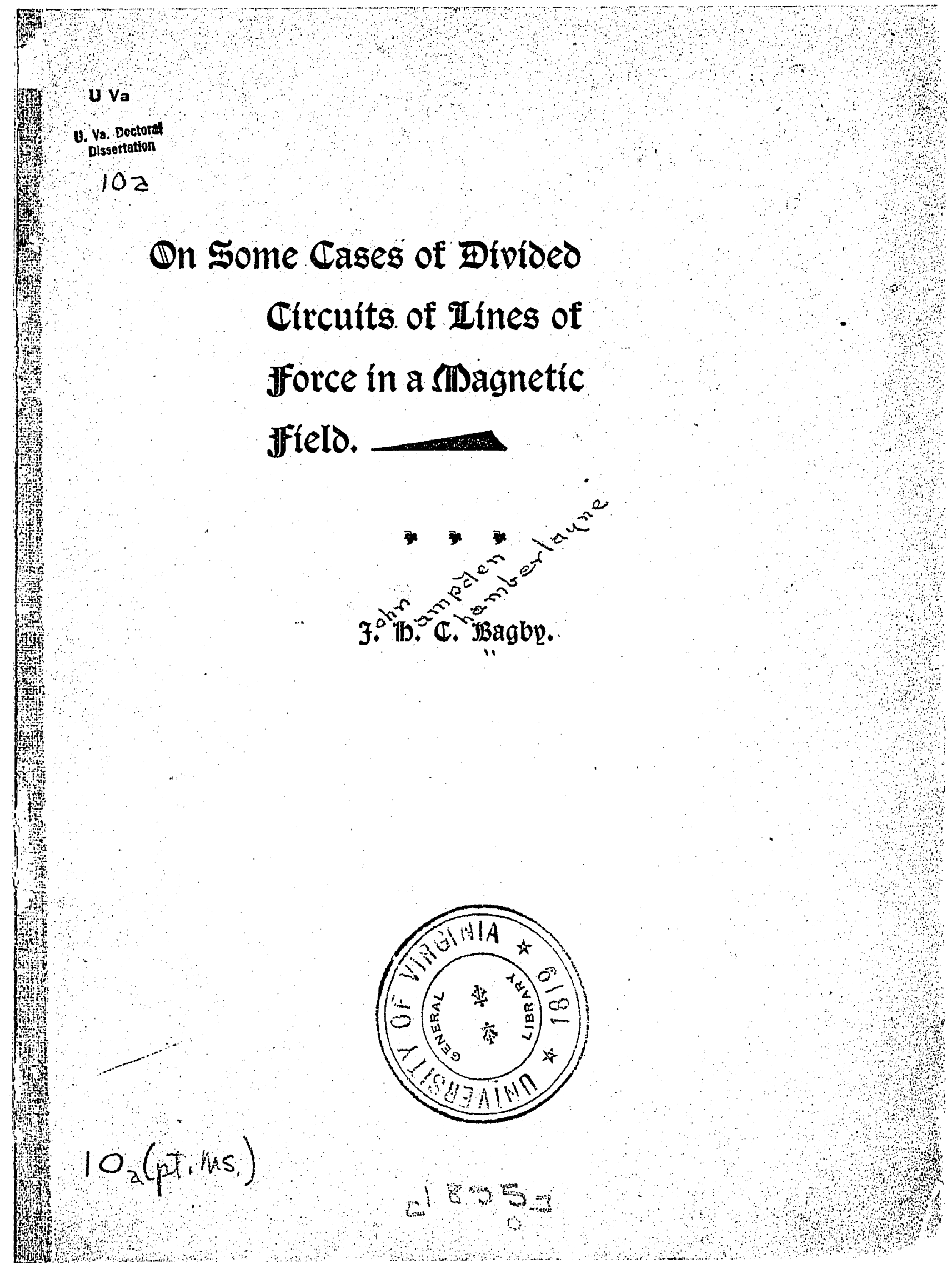


mis

Juit 5 :3

$$
\text { U. }
$$

U. Va. Doctoral

Dissertation

102

bis

The investigation upon which the following thesis was based formed a portion of the work in Natural Philosophy, leading to the Degree of Doctor of Philosophy, at the University of Virginia.

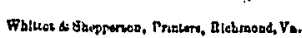




\section{ON SOME CASES OF DIVIDED CIRCUITS OF LINES OF FORCE IN A MAGNETIC FIELD.}

The rapid extension within the last few decacles of the practical use of the electric current and of machines employing electricity as their motive power, and the consequent value of a detailed linowledge of the functions of all parts of machines for generating or for utilizing electric currents, and of the circumstances necessary for attaining maximum efliciency, have led to a minute study of the performance of all commercial forms of such apparatus. In such tests the ultimate object has usually been the improvement of the machine in question, not a more exact knowledge of the causes involved, stripped of the modifications arising from the arrangement of the parts of the particular apparatus under investigation.

From the study of the early forms of dynamo machines, it was evident that the efficient performance of such machines was intimately bound up with the magnetic character of the cores of the field coils and with the forms and proportions of the different portions of the magnetic circuit. The general results of these inrestigations have been-(1), the use of material of high permeability in the metallic parts of the circuit; (2), the simplification of the circuit by forming it of a fer pieces of simple form, and by narrowing the airgap to the greatest degree practicable; (3), the use of ingenious derices for separating, as far as convenient, the magnetic circuit of the machine from other magnetic material (Hoplinson's zinc footstep, introduced into the Edison dynamo; the overhung armature of machines with the base serving as 


\section{$\left[\begin{array}{ll}2 & 2\end{array}\right]$}

the yolie-piece; the single, continuously wound " $\mathrm{C}$ " shaped field magnet of the C. \& C. machines, may be mentioned). The design has been throughout to concentrate into that portion of the magnetic circuit in which the armature rotates the largest possible fraction of the lines of magnetic force due to the ampere-turns of the field. This is to be attrined only by lowering the magnetic reluctance of the circuit, since in any case, save that of a continuous iron ring completely covered by the magnetizing coil, there is presented to the lines of force, in addition to the imperfect metallic circuit, an alternative shunt circuit through the air, of low permeability, but of large cross section. Into this shunt circuit some lines will leak, the more as the reluctance of the metallic circuit is greater. This conclusion might have been drawn a priori from the principle of the magnetic circuit," considered as strictly analogous to a conducting circuit in an electrolyte. $†$ This fact, as well as others, to which reference will be made later under the proper headings, can be decluced by a laborious process of comparison from the numerous measurements of waste fields made on various dynamo machines.+

Though much and varied information of a practical character had been gained by these careful measurements made by skilled observers, it still seemed desirable that measures should be made of the leakage and of the allied extension of magnetization along simple typical forms of magnetic circuits, such as long, straight rods and circular lings. These two forms are clealt with in the experiments recorded in the following parges.

The specimens dealt with were of the lighest commercial grade of soft annealed iron wire, long rods of No. 10 and No. 12, Brown \& Sharpe's gange,

* In the deduction of the equation of the magnetic cireuit it is amalytically impracticable to take this into account (Ewing, Nagnetization in Iron, de., p. 200); in dynamo clesign it is allowed for by the use of empirical coefficients proper to the typo of machine (Dynamo Machinery, J. Hopkinson, p. 87, etc.).

+ Ewing, Magnetization in Iron, \&ec., p. 262.

$\ddagger$ See Dynamo Machinery, J. Hoplinson, pp. 98-101, 127-131; Dynamo-Electric Machinery, S. P. Thompson, p. 182, seq.; The Dynamo, Hawkins and Wallis, p. 270, seq.; Magnetization in Iron, de., J. A. Ewing. Numerous references to original papers are given. 


\section{$\left[\begin{array}{ll}3 & ]\end{array}\right.$}

and a ring of No. 4 on the same scale. Each piece, after having been prepared for use, was carefully annealed to wipe out any hardening effects due to handling, thus ensuring that the iron was magnetically soft at the beginning of the experiment. After each series of measures was completed the wire was slowly demagnetized by reversals to bring it back to its initial neutral condition. When in any experiment the iron had been hardened by stretcling beyoud its elastic limit, no attempt was made to overcome this, but a fresh piece was used for the next series of measurements. The ballistic method, with reversal of the magnetizing current, was used throughont to measure the induction, the instrument used being a large galvanometer of the Wiedemann form, from which the damping blocks had been removed. With the magnetic system suspended by a single fibre of unspun silk, and the earth's field neutralized by means of bar magnets, the period of a single swing was found to be about ten seconds. The readings were taken, as usual, with a telescope and scale. The mean of a number of trials by Thomson's method * showed that one scale division corresponded to the reversal of 61.6 lines of force through 100 turns of wire in the exploring coil. This value has been used in the reduction of the observations. The magnetizing current was measured by a horizontal galvanometer, whose constant, the weighted mean of three measurements with the copper voltameter, showed a current of 5.71 milliamperes for 1 degree deflection. This galvanometer was placed so as to be under the eye of the observer at the telescope, within whose reach was a resistance box to control the current, a Bertin reversing liey in the circuit of the exciting coil, and also a key by means of which the ballistic galvanometer circuit could be broken when the current was being changed or the exploring coil shifted. Trial showed that the presence of the horizontal galvanometer in the same roorn with the ballistic galvanometer caused no sensible error, the effect, though detectable under careful scrutiny, being so small as to elude measurement.

* Magnetization in Iron, de., Ewing, p. 62. 


\section{$\left[\begin{array}{ll}4 & \end{array}\right]$}

A preliminary series of measures was made to determine the proper method of suspending the wires, the best way of applying tension, etc. The wire used in this case was of No. 10 gauge, $98 \mathrm{~cm}$. long, suspended vertically. Several of the results obtained have been incorporated in the present paper in Tables I. and II. The effect of the vertical component of the earth's field was not taken into account, as the trial showed that the corresponding readings with the wire in the vertical position and in the horizontal plane perpendicular to the magnetic meridian were sensibly the same, the differences falling well within the range of the errors of observation. In Table I., plotted in Fig. 1, is shown the effect of the position of the mag-

TABLE I.

\begin{tabular}{|c|c|c|}
\hline \multirow{2}{*}{$\begin{array}{l}\text { Distance from Exoming } \\
\text { CoIr. }\end{array}$} & \multicolumn{2}{|c|}{ - _ _ _ _ THROW _ _ _ _ } \\
\hline & Coll. $A T$ MIIDdLe. & Coil at End. \\
\hline $0 \mathrm{~cm}$. & 6.3 & 6.0 \\
\hline 1 " & 5.1 & 4.8 \\
\hline 2 “ & 4.1 & 3.8 \\
\hline$\overline{3}$ ، & $3 . t$ & 3.1 \\
\hline 4 " & 2.8 & 2.4 \\
\hline 5 & 2.1 & 1.9 \\
\hline $6 " 6$ & 1.6 & 1.4 \\
\hline $7 \lll$ & 12 & 1.0 \\
\hline $8 "$ & 0.9 & 0.8 \\
\hline 9 “ & 0.8 & 0.6 \\
\hline $10 "$ & 0.7 & 0.3 \\
\hline $12 "$ & 0.5 & 0.1 \\
\hline 14 " & 0.4 & \\
\hline
\end{tabular}

netizing coil on the leakage from the wire. From the figure it is seen that the symmetrical disposition of the iron relative to this coil heightens the induction and promotes the extension of the lines along the wire. In all 


\section{$\left[\begin{array}{ll}5 & ]\end{array}\right.$}

experiments, therefore, the middle position was chosen for the exciting coil. In Table II., plotted in Fig. 2, the effect of approaching saturation on the leakage is exhibited. With increase of induction the leakage becomes more rapid, the curve rising more and more steeply. This result is in accord with the experience of dynamo designers, who avoid saturation on account of the large waste field which accompanies it." As no means were at hand to callibrate the ballistic galvanometer used in taking these measures, the vertical

TABLE II.

\begin{tabular}{|c|c|c|c|c|}
\hline \multirow[b]{2}{*}{ Distance. } & \multicolumn{4}{|c|}{-THrow For B EQTaL to } \\
\hline & 10,300 . & 14,100 . & 16,400 . & 18,000 \\
\hline 0 & 60 & 8.0 & 10.0 & 10.4 \\
\hline 1 & 4.8 & 6.7 & 8.0 & 8.3 \\
\hline $\overrightarrow{2}$ & 3.8 & 5.5 & 6.7 & 6.9 \\
\hline 3 & 3.1 & 4.4 & 5.2 & 5.8 \\
\hline 4 & 2.4 & 3.6 & 4.0 & 4.4 \\
\hline 5 & 1.9 & 2.7 & 3.3 & 3.6 \\
\hline 6 & 1.4 & 2.0 & 2.6 & 2.8 \\
\hline 7 & 1.0 & 1.4 & 1.9 & 2.1 \\
\hline 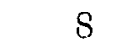 & 0.8 & 1.0 & 1.4 & 1.6 \\
\hline 9 & 0.6 & 0.8 & 1.0 & 1.1 \\
\hline 10 & 0.3 & 0.5 & 0.7 & 0.9 \\
\hline 12 & 0.1 & 0.3 & 0.4 & 0.5 \\
\hline 14 & & 0.1 & 0.2 & 0.3 \\
\hline 16 & & & & 0.1 \\
\hline
\end{tabular}

scale of the figures is the arbitrary one of cleflections. This, however, does not affect the validity of the conclusions drawn, as the callibration would not change the shape or the relative positions of the curres, but would only furnish the vertical scale in terms of C. G. S. units of induction.

* Dynamo-Electric Machinery, S. P. Thompson, p. 184; The Dynamo, Hawhins \& Wallis, p. 309, seq. 


\section{[ $6 \begin{array}{ll}6 & ]\end{array}$}

In the remaining experiments on long wires size No. 12 was used, the wire boing slung in a horizontal position perpendicular to the magnetic meridian. One end was attached to the short arm of a bell crank lever of steel, by means of which tensions up to 150 kilograms could be applied. The other end of the wire was threacled through an eyelet in a round steel rod fitting smoothly in a heavy iron block bolted to the table; the farther end of this rod was fitted with a screw-thread and nut, which transmitted the pressure to the back surface of the iron block. By turning this nut the rod, and with it the wire, could be drawn along so as to compensate for any elastic lengthening of the wire under tension, and thus maintain a constant tension by keeping the long arm of the lever always horizontal. A set screw working in the iron block was used to clamp the steel rod in any position to which it and the attached wire had been rotated. A light pointer attached to the wire indicated on a vertical compass card the angular rotation produced, which could be varied at will by rotating the steel rod in its cylindrical seat.

Table III. and Fig. 3 give the leakage curve for this wire, the distances being measured from the middle point of the magnetizing coil, and the ordinates giving the induction at the corresponding distances.

TABLE III.

\begin{tabular}{|c|c|c|c|c|c|}
\hline Distaxoe. & Tinrot. & $\mathrm{B}$. & Dispaxon. & Trmow. & B. \\
\hline .0 & 21.6 & 16960 & 8.5 & 2.9 & 2740 \\
\hline 4.4 & 13.2 & 12550 & 9.0 & 2.2 & 2080 \\
\hline 5.0 & 10.9 & 10360 & 10.0 & 1.4 & 1330 \\
\hline 5.5 & 9.2 & 8730 & 11.0 & 0.9 & 850 \\
\hline 6.0 & 7.9 & 7500 & 12.0 & 0.5 & 470 \\
\hline 6.5 & 6.4 & 6080 & 13.0 & 0.3 & 280 \\
\hline 7.0 & 5.3 & 5030 & 14.0 & 0.2 & 190 \\
\hline 7.5 & 4.4 & 4180 & 15.0 & 0.1 & 90 \\
\hline 8.0 & 3.7 & 3520 & 16.0 & trace. & \\
\hline
\end{tabular}




\section{$\left[\begin{array}{ll} & 7\end{array}\right]$}

With the wire in position measurements were taken to find the magnetization and permeability of the iron employed. The data are given in Table IV. and the curves in Fig. 4. The magnetism indnced on the surface of the wire by the leakage shown in Fig. 3 has exerted so strong a demagnetizing force*

\begin{tabular}{|c|c|c|c|c|}
\hline \multicolumn{5}{|c|}{ TABLE IV. } \\
\hline Cutrrext. & II. & Turow. & B. & $\mu$ \\
\hline 0.0143 & 2.01 & 0.1 & 115 & 57 \\
\hline 0.0157 & 2.21 & 0.2 & 298 & 134 \\
\hline 0.0186 & 2.61 & $0.2+$ & 378 & $14 t$ \\
\hline 0.0200 & 2.81 & 0.3 & 466 & 165 \\
\hline 0.0229 & 3.22 & $0.3+$ & 546 & 169 \\
\hline 0.0272 & 3.82 & $0.3+$ & & \\
\hline 0.0300 & 4.23 & 0.4 & 602 & 142 \\
\hline 0.0329 & 4.63 & $0.4+$ & 682 & 147 \\
\hline 0.0373 & 5.24 & $0 . \tilde{5}$ & 753 & 144 \\
\hline 0.0401 & 5.65 & 0.6 & 929 & 164 \\
\hline 0.0489 & 6.88 & 0.7 & 1071 & 155 \\
\hline 0.0591 & 8.32 & $0.8+$ & 1309 & 157 \\
\hline 0.0725 & 10.2 & $1.3-$ & 2080 & 204 \\
\hline 0.0922 & 13.0 & 2.7 & 4630 & 357 \\
\hline 0.1490 & 20.9 & $5.6+$ & 9830 & 470 \\
\hline 0.1560 & 22.0 & 6.0 & 10550 & 480 \\
\hline 0.1670 & 23.4 & $6.3+$ & 11080 & 473 \\
\hline 0.1960 & 27.6 & 7.2 & 12650 & 458 \\
\hline 0.2120 & 29.9 & 7.5 & 13180 & 441 \\
\hline 0.2290 & 32.2 & 7.8 & 13610 & 423 \\
\hline 0.3000 & 42.2 & 8.3 & $1 \pm 160$ & 359 \\
\hline 0.3390 & 47.6 & 8.9 & $1+4500$ & 305 \\
\hline $0.40 \div 0$ & 56.8 & $9.1-$ & 15180 & 267 \\
\hline 0.5660 & 79.7 & 9.9 & 16180 & 203 \\
\hline 0.6210 & 87.3 & 10.5 & 16700 & 191 \\
\hline 0.6770 & 95.3 & $10.8+$ & 16960 & 178 \\
\hline
\end{tabular}

*.Iragnetization in Iron, \&c., J. A. Ewing, pp. 21 and 32 ; Alternate Current Transformer, A. J. Fleming, I., p. 28; Mascart and Joubert, Vol. II., p. 636. 
as to shear the magnetization curve along the axis of $\mathrm{H}$, and thus lower the value of $\mu$ greatly. The errors of obserration, very sensible in the small deflections along the first portion of the curves, have entered with increased effect into the values of $\mu$, and cause an irregular grouping of the values corresponding to the smaller values of $H$. The other portions of the curve are of the normal shape.

The point next taken up was the relation between the induction and the extension of the magnetic force along the wire. In maling these measurements it was found impossible to find any definite point beyond which it could be said that the magnetization did not extend, the ballistic throws becoming smaller until no effect could bo detected on reversing the current. If, however, the reversing of the current were continued, being so timed as to correspond to the period of the galvanometer needle, it was found that the insensible deflections could be added to produce finally a deflection of any desired magnitude. By this artifice the induction could be certainly traced to a distance three times as great as that given in Fig. 3. No accurate measurement could, however, be made of the induction at any point in this way, for, though the measurements showed a progressive decrease with increase of distance, it was impossible to so accurately synchronize the reversal of current with the swing of the needle as to get, at a given distance, a constant and invariable value for the induction. In order, therefore, to obtain reliable data from which to deduce the connection between the induction and the extension of the lines of force, those distances were determined at which a throw of one scale division was observed. The same method was used in the experiments on the effects of tension and torsion. Table V. and Fig. 5 show that for an increase of induction there is an increase of extension, but the two increments are not proportional. The curve resembles the parabola, but probably is asymptotic to some line parallel to the axis of induction and at a finite distance from it. 
[ $9 \begin{array}{ll}9 & ]\end{array}$

TABLE $V$.

\begin{tabular}{|c|c|c|c|}
\hline INDUCrION. & Distayce. & Irvtortos. & Distanoe. \\
\hline $\begin{array}{r}2000 \\
4900 \\
6600 \\
9300 \\
11400 \\
13600\end{array}$ & $\begin{array}{l}4.4 \mathrm{~cm} . \\
5.4 ، \\
6.5 ، \\
7.3 ، \\
8.3 ، \\
8.5\end{array}$ & $\begin{array}{l}14200 \\
14500 \\
15400 \\
16500 \\
16750\end{array}$ & $\begin{array}{r}9.4 \mathrm{~cm} . \\
9.8 “ \\
10.0 ، \\
10.2 “ \\
10.3\end{array}$ \\
\hline
\end{tabular}

Table VI. and Fig. 6 exhibit the effect of increasing stress on the extension of the lines of force. The curve shows a gralual increase of distance, followed by a more gradual decrease, as the iron began to become hardened by the stress, the elastic limit being reached at about $178.1 \times 10^{\circ}$ dynes per sq. cm.* For a certain range on either side of this point the elongation remains sensibly the same, afterward decreasing for increasing strain on the hardened iron. In its general characteristics this curve resembles the permeability curve for iron under similar conclitions.t In this experiment, as

\begin{tabular}{|c|c|c|c|c|c|c|c|}
\hline \multicolumn{8}{|c|}{ TABLE VI. } \\
\hline \multicolumn{2}{|c|}{ Texsios. } & \multirow{2}{*}{$\begin{array}{c}\begin{array}{c}\text { Extex- } \\
\text { s10x. }\end{array} \\
7.50 \\
7.55 \\
7.60 \\
7.65 \\
7.70 \\
7.75\end{array}$} & \multicolumn{2}{|c|}{ Texsion. } & $\begin{array}{l}\text { Extwex- } \\
\text { s5ox. } \\
7.80\end{array}$ & Tession. & $\begin{array}{l}\text { Exten- } \\
\text { sION. }\end{array}$ \\
\hline 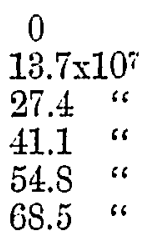 & $\begin{array}{c}\text { Dynes. } \\
" ، \\
" \\
" 6 \\
\text { " }\end{array}$ & & $\begin{array}{r}82.2 \\
95.9 \\
109.6 \\
123.3 \\
137.0 \\
150.7\end{array}$ & $\begin{array}{c}10 \\
" \text { Dynes. } \\
" 6 \\
" 6 \\
" \\
" \\
" \\
"\end{array}$ & $\begin{array}{l}7.80 \\
7.85+ \\
7.75 \\
7.70 \\
7.70 \\
7.70\end{array}$ & 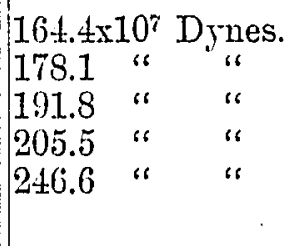 & $\begin{array}{l}7.70- \\
7.70- \\
7.65+ \\
7.60\end{array}$ \\
\hline
\end{tabular}

* Corresponding to 25,000 pounds per square inch; Mechanics of Materials, MLerriman + Magnetization in Iron, \&e., Ewing, p. 197, seq.

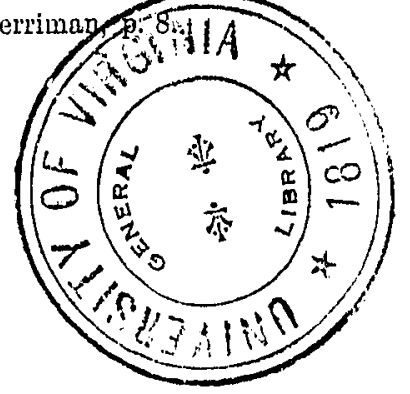


well as in the next on the effect of torsion, changes of stress were made with the wire demagnetized.

The effects of torsional strain are found in Table VII. and Fig. 7. Here the effects are similar to those of tension, but the drop of the latter portion of the curve is more marked. On gradually reducing the torsion the curve rose, but not to the sime height as initially-an effect of hysteresis that was to have been anticipated. The curve shows a general similarity of structure to the permeability curve determined under like conditions, the curvatures not being so decided, howerer, in this case."

TABLE VII.

\begin{tabular}{|c|c|c|c|c|c|c|c|}
\hline \multicolumn{3}{|c|}{ Tonsios. } & $\frac{\text { Extexsion. }}{7.00}$ & \multicolumn{3}{|c|}{ Tonsion. } & $\frac{\text { Extexsion. }}{6.40}$ \\
\hline $\begin{array}{l}0 \\
\frac{1}{1} \\
\frac{1}{2} \\
\frac{3}{3} \\
1 \\
2\end{array}$ & $\begin{array}{c}\text { Degr } \\
" 6 \\
" 6 \\
" 6 \\
" 6\end{array}$ & $\begin{array}{l}e r " c m . \\
" 6 \\
" 6 \\
" 6 \\
" 6\end{array}$ & $\begin{array}{l}7.00 \\
7.05 \\
7.05 \\
7.10- \\
7.05 \\
6.70 \\
6.50\end{array}$ & $\begin{array}{l}2 \frac{1}{2} \\
3 \\
3 \frac{1}{2} \\
4 \\
4 \frac{1}{2} \\
5 \\
0\end{array}$ & $\begin{array}{l}\text { "6re } \\
\text { " } \\
\text { " } \\
\text { " }\end{array}$ & $\begin{array}{l}\text { el" } \mathrm{cm} . \\
6 \\
6 \\
" 6 \\
" 6 \\
" 6\end{array}$ & $\begin{array}{l}6.40 \\
6.30 \\
6.20 \\
6.15 \\
6.05+ \\
6.05 \\
6.80\end{array}$ \\
\hline
\end{tabular}

The general conclusion is, that whatever increases the permeability of the material thereby forces the lines of force further along the wire. If we may assume that the application of varions linds of stress leaves the inducing field unchanged (true, certainly, as a first approximation), it follows at once that whatever increases the permeability will cause a greater induction throngh any cross section of the wire, and will thus canse the point at which any given number of lines of force is fornd to advance, and vice ver'sc. A more interesting point arises in connection with the measurement of the

* Mragnetiation in Iron, fe., Ewing, p. 220. In this case the field was kept constant while torsion was boing applied. 


\section{[ 111$]$}

maximum extension of the lines of force. It seems generally held, that of the lines of force threading a solenoid some complete their circuits in small, contracted loops; others in larger; others still in loops of a span so great that the lines leave the solenoid parallel to its axis and remain sensibly so for some distance, a few to any specified distance. If this be rigorously true, and the field be undisturbed in its general arrangement, though not in magnitude, by the induced magnetism, then, in view of Lord Rayleigh's discovery of the constant permeability of iron in weak fields, * there should be lines of induction through any and all cross-sections of the wire, becoming, at distances great, relative to the size of the wire, too few to be detected by any means at our command. The correctness of this riew is rendered the more probable by the measurements of Table III., the curve of Fig. 3 dropping steeply in its first portion outside the exciting coil, then tending to become asymptotic to the line of zero induction.

For the experiments on the leakage around a circular circuit a ring of No. 4, B. \& S. gange, annealed soft iron wire, $20.8 \mathrm{~cm}$. in cliameter, was used; on this was wound a magnetizing coil $2.2 \mathrm{~cm}$. long, beneath the middle of which, close to the surface of the iron, was placed a secondary or reading coil $0.5 \mathrm{~cm}$. long. A second movable reading coil of the same dimensions could be slipped along the ring and its position measured on a compass card placed concentrically within the iron ring. By this means measurements were made at 12 degrees intervals, measured from the midlle of the exciting coil, which itself occupied an arc of 12 degrees on the wire ring. A series of readings was first taken to determine the magnetization and permeability curves for the circuit, as arranged for the leakage experiments. Table VIII. and Fig. 8 show plainly the strong demagnetizing effect t of the free magnetism induced on the surface of the wire by the leakage of the magnetic lines

- * Magnetization in Fron, do., Ewing, p. 120. The effect of the free surface magnetism due to leakage in keoping up the strength of field in the wire will be found on p. 263 .

t Magnetization of Iron, de., Ewing, p. 203. 


\section{$\left[\begin{array}{ll}12 & ]\end{array}\right.$}

of force, the curves exhibiting the form proper to those of a rather hard steel or of a short ellipsoid.*

\begin{tabular}{|c|c|c|c|c|}
\hline \multicolumn{5}{|c|}{ TABLE VIII. } \\
\hline Conrext. & H. & Turow. & B. & $\mu$. \\
\hline 0.0228 & 1.46 & 0.4 & 117 & 80.3 \\
\hline 0.0457 & 2.92 & 0.8 & $23 \pm$ & 80.3 \\
\hline 0.0572 & 3.66 & $1.0-$ & 293 & 80.1 \\
\hline 0.0774 & 4.95 & $1.3+$ & 391 & 77.1 \\
\hline 0.112 & 7.19 & $2.0-$ & 600 & 83.5 \\
\hline 0.133 & 8.51 & 2.5 & 760 & 89.5 \\
\hline 0.175 & 11.2 & 3.4 & 1040 & 92.5 \\
\hline 0.206 & 13.2 & $3.5+$ & 1160 & 87.7 \\
\hline 0.241 & 15.4 & 4.6 & 1380 & 91.0 \\
\hline 0.274 & 17.5 & 5.4 & 1650 & 94.0 \\
\hline 0.312 & 19.9 & 6.3 & 1920 & 96.4 \\
\hline 0.340 & 21.7 & 7.0 & 2130 & 98.2 \\
\hline 0.385 & 24.6 & 8.3 & 2530 & 103. \\
\hline 0.457 & 29.3 & 10.8 & 3290 & 112. \\
\hline 0.502 & 32.0 & 12.3 & 3750 & 117. \\
\hline 0.568 & 36.3 & 14.9 & 4540 & 125. \\
\hline 0.654 & 41.8 & 17.6 & 5360 & 128. \\
\hline 0.752 & 48.1 & 22.6 & 6880 & 143. \\
\hline 0.934 & 59.7 & 29.4 & 8920 & 149. \\
\hline 1.230 & 78.6 & 40.4 & 12310 & 157. \\
\hline
\end{tabular}

In Table IX. and Fig, 9 and 9 bis is given the leaknge curve for the solid ring under a field of $58 \mathrm{C}$. G. S. units, the curve being drawn both on a straight base and on a circular base. As shown in these figures, the leakage curve is of the same type as that for the straight wire in Fig. 3 . In the former the drop in the curve is much less rapid, the curved shape of the iron conferring upon it a greater power of retaining the lines within the metal.

* Magnetization in Iron, ec., Ewing, p. 82, seq., and p. 264, seq. ; The Dynamo, Hawkins \& Wallis, Chap. III.; Alternate Current Transformer, A. J. Fleming, II., p. 108. 


\section{[ 13 ]}

The portions of the curves lying within the magnetizing coils are different, the longer coil maintaining a more miform field nẹar its central part.

\begin{tabular}{|c|c|c|c|c|c|}
\hline \multicolumn{6}{|c|}{ TABLE IX. } \\
\hline AxGLE. & Trurow. & B. & ANGLE. & Throw. & B. \\
\hline 0 Degrees. & 29.2 & 8880 & 96 Degrees. & 5.6 & 1,640 \\
\hline 12 & 23.6 & 6920 & 108 & 4.7 & 1,380 \\
\hline 24 & 18.9 & 5540 & 120 & 3.9 & 1,140 \\
\hline 36 & 15.4 & 4520 & 132 & 3.3 & 970 \\
\hline 48 " & 12.5 & 3670 & 144 & 2.8 & 820 \\
\hline 60 & 10.3 & 3020 & 156 & 2.3 & 670 \\
\hline $72 \quad$ “ & 8.2 & 2410 & 168 & 2.0 & 590 \\
\hline S4 " " & 6.8 & 1990 & 180 & 2.0 & 590 \\
\hline
\end{tabular}

Air gaps of widtlis $0.1 \mathrm{~cm} ., 0.5 \mathrm{~cm}$, and $1.0 \mathrm{~cm}$. were then successively made in the ring, the.iron being clemagnetized by reversals and well annealed after each cutting to reduce it to its initial passive state. Readings were in each case taken with the air-gap at 180 degrees, 90 degrees, and 0 degrees from the middle point of the exciting coil; also, at 135 degrees and 45 degrees in case of the air-gap $0.1 \mathrm{~cm}$. The results of these readings are given in Tables X., XI., and XII. and Fig. 10, and 10 bis, 11 and 12. A consicleration and comparison of these several figures, all drawn to the same scale, brings to light several points of interest:

1. The introduction into the metallic magnetic circuit of resistance in the shape of the air-gap causes a more rapid leakage into the shunt circuit through the air, whose resistance is relatively decreased, and by this, as well as by the effect of the ends of the wire produced by the cutting, increases the demagnetizing force, and thus decreases the induction at all points on the wire, this effect becoming more marked as the gap is widened.

2. As might have been asserted in advance, a symmetrical position of the 


\section{[ 14 ]}

air-gap produces a symmetrical leakage curve, and vice versa, the asymmetry being greater as the gap is wider and nearer to the exciting coil.

\begin{tabular}{|c|c|c|c|c|c|c|}
\hline \multicolumn{7}{|c|}{ TABLE X. } \\
\hline \multicolumn{2}{|c|}{ ANGLE. } & 180 DEGREES. & $\begin{array}{l}\text {-VALUE OF B } \\
\text { |.135 DEgREES. }\end{array}$ & $\begin{array}{l}\text { FOR GAP OF } \\
90 \text { DEGREES. }\end{array}$ & $\begin{array}{l}0.1 \text { CMI. AT- } \\
45 \text { DeGreEs. }\end{array}$ & 0 DEGHEES. \\
\hline \multicolumn{2}{|c|}{0 Deg's. } & 8830 & 8770 & 7450 & 6880 & 1700 \\
\hline 12 & $66^{-6}$ & 6950 & 6770 & 5250 & 4900 & 1500 \\
\hline 24 & & 5450 & 5340 & 3810 & 3080 & 1030 \\
\hline 36 & & 4520 & 4490 & 3200 & 1820 & 700 \\
\hline 48 & & 3630 & 3600 & 2350 & 700 & 530 \\
\hline 60 & “6 & 2990 & 2930 & 1790 & 500 & 360 \\
\hline 72 & 66 & 2370 & 2320 & 1440 & 470 & 200 \\
\hline 84 & “ & 1790 & 1740 & 590 & 380 & 150 \\
\hline 96 & $"$ & 1530 & 1290 & 320 & 320 & 120 \\
\hline 108 & $" 6$ & 1140 & 870 & 310 & 260 & 90 \\
\hline 120 & " & 910 & 590 & 290 & 200 & 80 \\
\hline 132 & 6 & 760 & 230 & 260 & 170 & 60 \\
\hline 144 & $"$ & 590 & 230 & 230 & 150 & $\ldots$ \\
\hline 156 & 66 & 410 & 260 & 230 & 140 & $\ldots$ \\
\hline 168 & 6 & 290 & 290 & 200 & 150 & $\cdots$ \\
\hline 180 & 66 & 150 & 320 & 230 & 170 & 30 \\
\hline-168 & 66 & 290 & 380 & 260 & 180 & $\cdots$ \\
\hline 156 & ss & 410 & 470 & 320 & 220 & $\cdots$ \\
\hline 144 & "s & 590 & 590 & 380 & 260 & $\cdots$ \\
\hline 132 & 66 & 760 & 700 & 500 & 360 & 60 \\
\hline 120 & " & 910 & 870 & 620 & 470 & 80 \\
\hline 108 & " & 1140 & 1140 & 820 & 620 & 90 \\
\hline 96 & “6 & 1530 & 1440 & 1030 & 790 & 120 \\
\hline 84 & & 1790 & 1870 & 1350 & 1030 & 150 \\
\hline 72 & "6 & 2370 & 2260 & 1670 & 1350 & 200 \\
\hline 60 & $" 6$ & 2990 & 2870 & 2110 & 1700 & 360 \\
\hline 48 & "6 & 3630 & 3550 & 2580 & 2140 & 530 \\
\hline 36 & "6 & 4520 & 4340 & 3200 & 2670 & 700 \\
\hline 24 & 6. & 5450 & 5310 & 4080 & 3290 & 1030 \\
\hline 12 & “ & 6950 & 6750 & 5220 & 4340 & 1500 \\
\hline Gap & & 150 & 200 & 290 & 700 & 1700 \\
\hline
\end{tabular}




\section{[. 15 ]}

3. With the gap at 180 degrees the minimum induction is in the gap. When the gap is shifted the point of minimum induction is displaced in the same direction; to the same extent as the gap for a slight clisplacement, if the gap be small; if the gap be large, to the same extent as the gap for any displacement.

\begin{tabular}{|c|c|c|c|}
\hline \multicolumn{4}{|c|}{ TABLE XI. } \\
\hline \multirow[b]{2}{*}{ ANGLE. } & $\longrightarrow-B$ & R-GAP OF 0 & 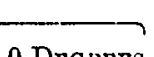 \\
\hline & 180 Degrees. & 90 DFG1REES. & 0 DEGREES. \\
\hline 0 Degrees. & 8450 & 7270 & 410 \\
\hline 12 & 6100 & 5400 & 530 \\
\hline & 4810 & 4340 & 410 \\
\hline 36 & 3900 & 3200 & 260 \\
\hline & 3080 & 2410 & 200 \\
\hline & 2550 & 1640 & 150 \\
\hline & 1940 & 1090 & 90 \\
\hline 84 & 1590 & 440 & 60 \\
\hline & 1350 & 150 & 30 \\
\hline 108 & 1090 & 200 & $\ldots$ \\
\hline 120 & 870 & 210 & $\cdots$ \\
\hline 132 & 670 & 210 & Trace. \\
\hline 144 & 470 & 230 & $\ldots$ \\
\hline 156 & 320 & 240 & $\ldots$ \\
\hline 168 ، & 170 & 270 & \\
\hline 180 & 60 & 280 & Trace. \\
\hline Gap. & 60 & 90 & 410 \\
\hline
\end{tabular}

4. The shifting of the gap causes a decrease in the induction in that part of the ring between it and the exciting coil, an increase along the opposite portion of the ring; so that, although the maximum induction be less for the case of the shifted gap, the leakage along the distant side is more gradual, and the induction near 180 degrees is greater.

5. Naturally for gaps of different widths the induction through the gap is less as the gap is wider. For a gap of constant width, the induction through it is greater as the gap is nearer to the exciting coil. 


\section{$\left[\begin{array}{ll}16 & ]\end{array}\right.$}

6. When the gap is placed at the middle of the magnetizing coil, the effect on the induction is very marked, the least decrease thus caused being 81 per cent. In the case of the gaps of widths $0.5 \mathrm{~cm}$. and $1.0 \mathrm{~cm}$. thus sit-

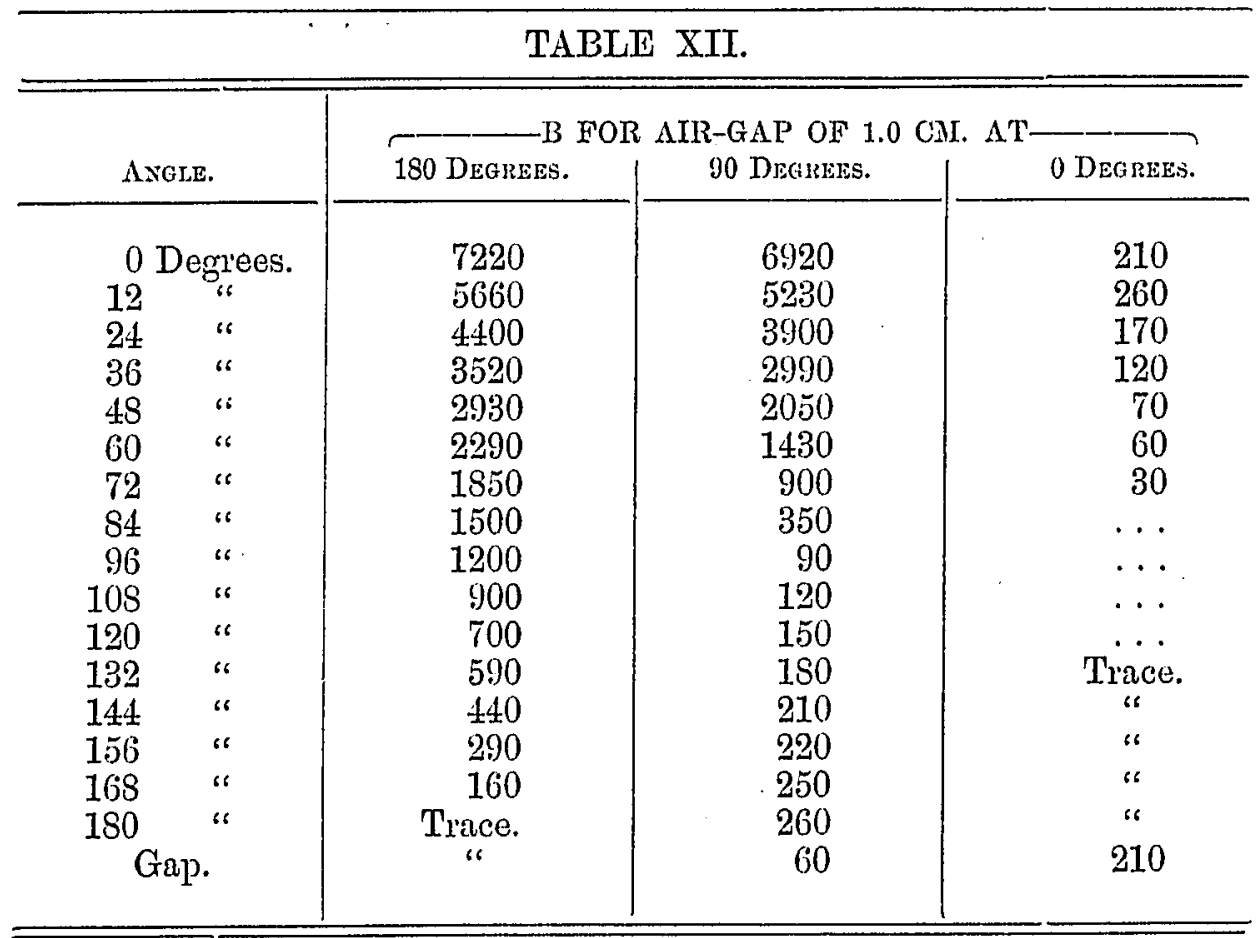

uated, being respectively once and twice the width of the reading coil, the induction at the middle of the magnetizing coil as measured is less than that found at a distance from the end of the coil equal to half its length. This peculiar effect is most probably due to the curved paths taken by the lines of force leaking out near the edge of the gap, which causes them to pass outside the space contained in the reading coil, and thus escape measurement. The gradual slight slope of the crest of the curve for the $0.1 \mathrm{~cm}$. gap placed at 0 degrees is due probably to a less marked effect of the same general kind.
May, 1895.
J. H. C. BAGBY. 


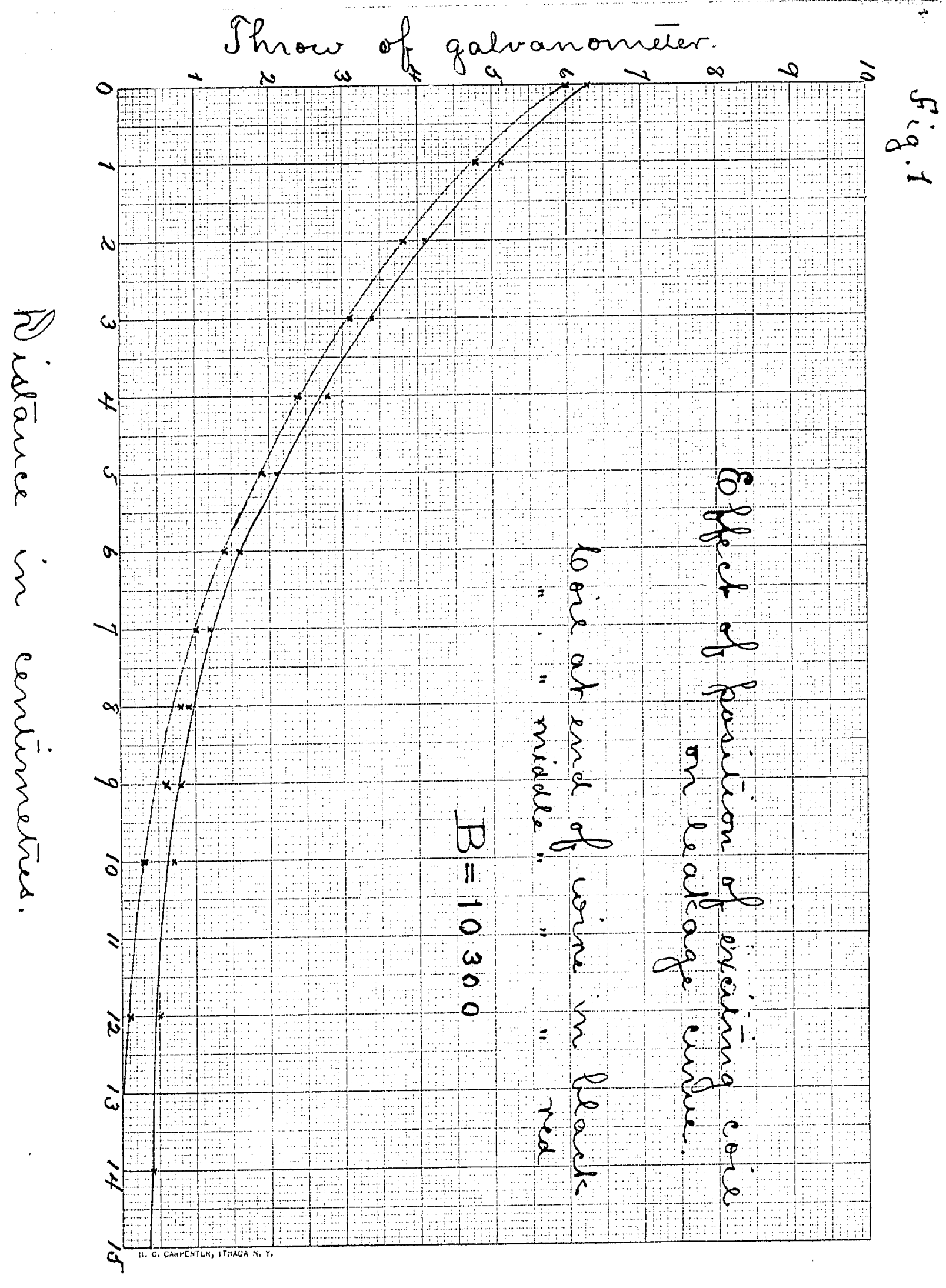




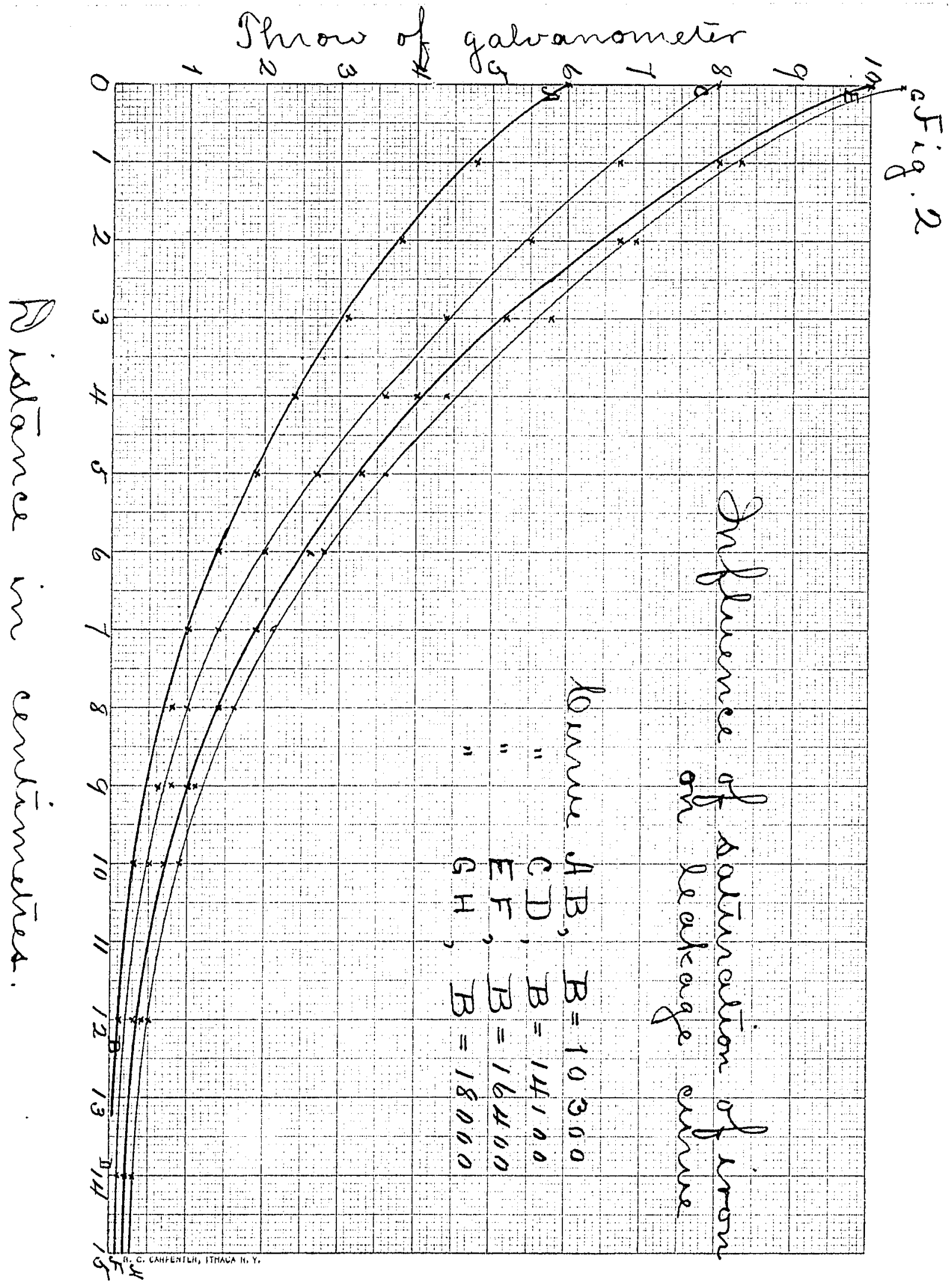




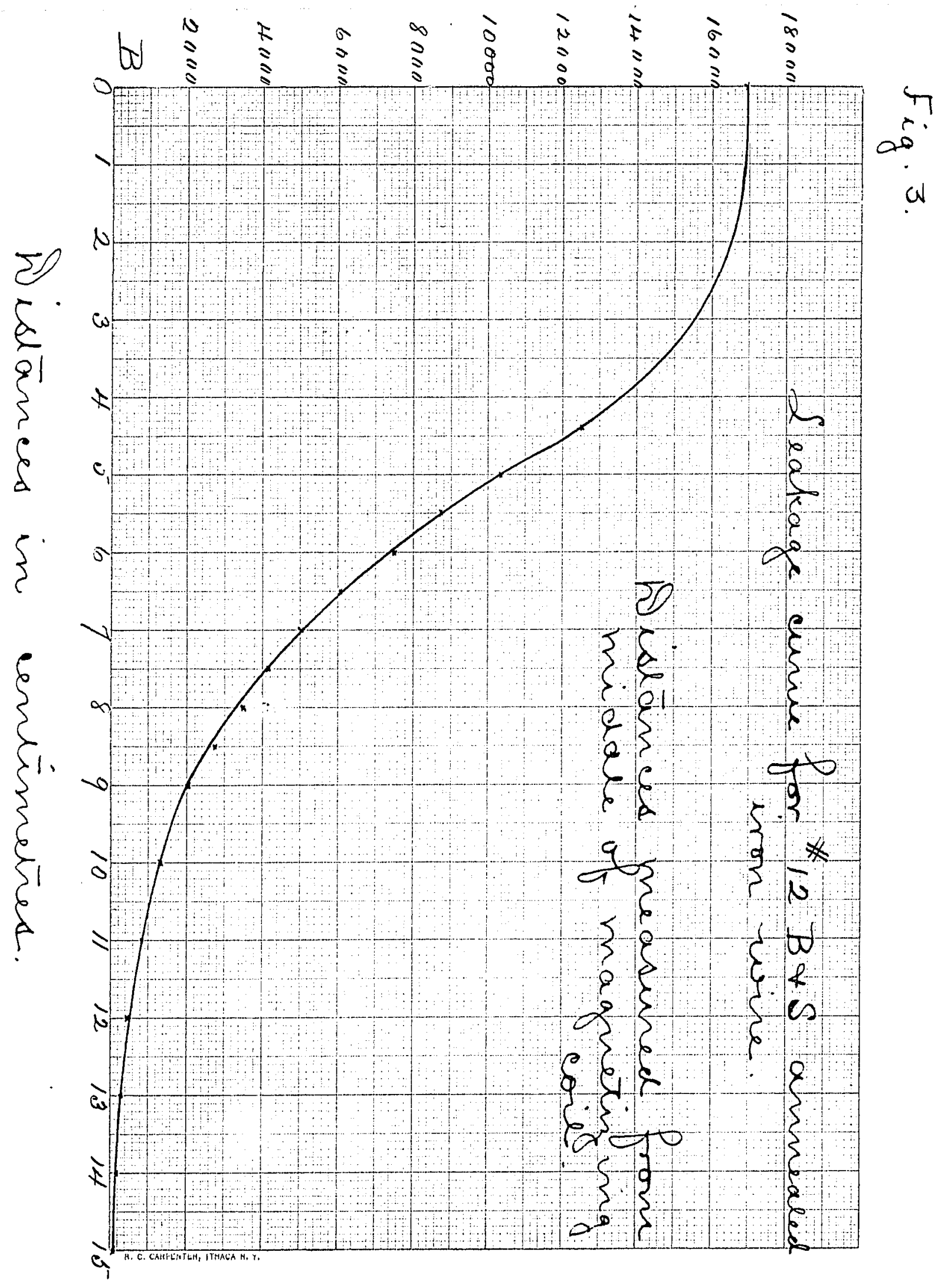




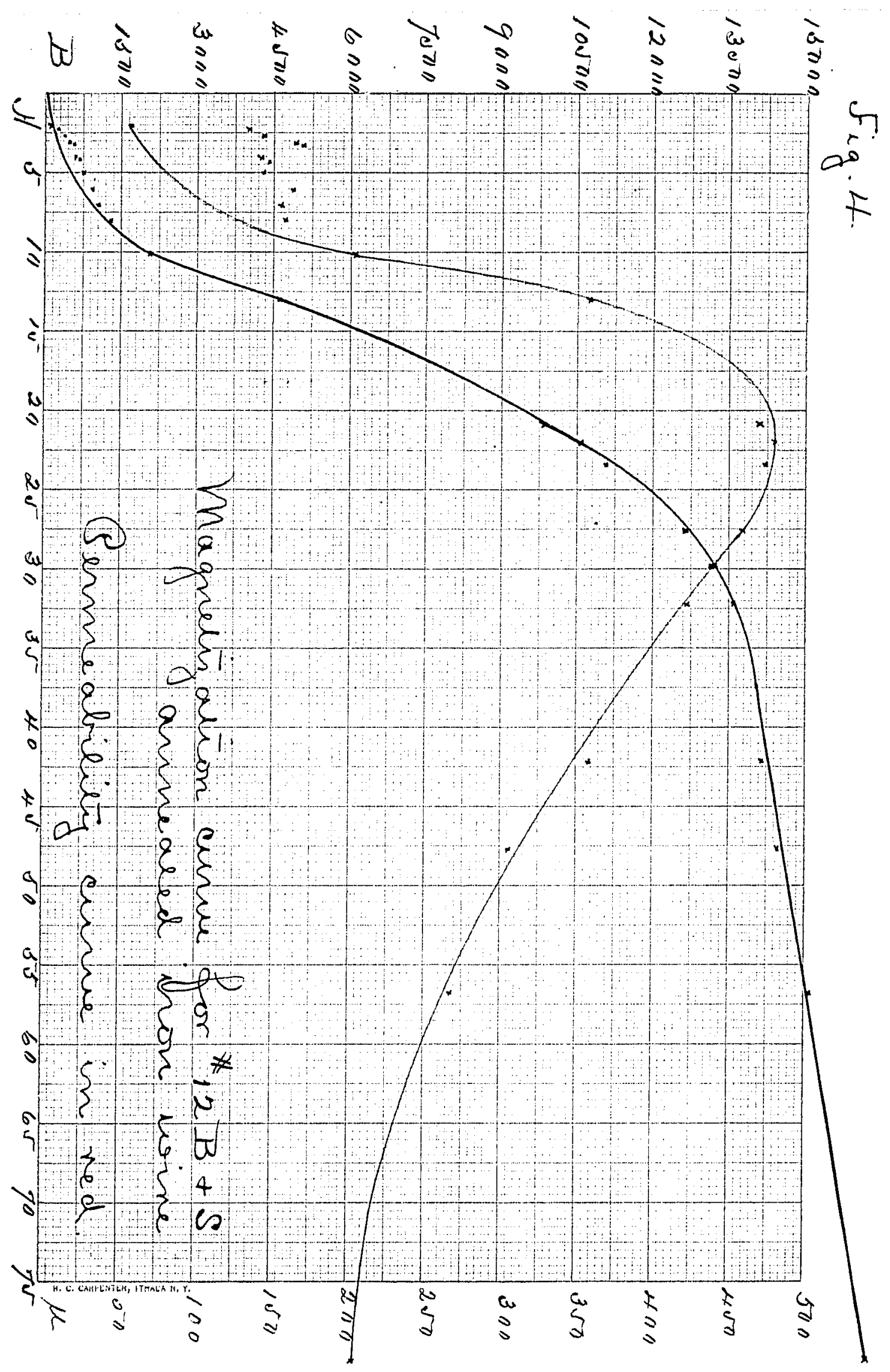




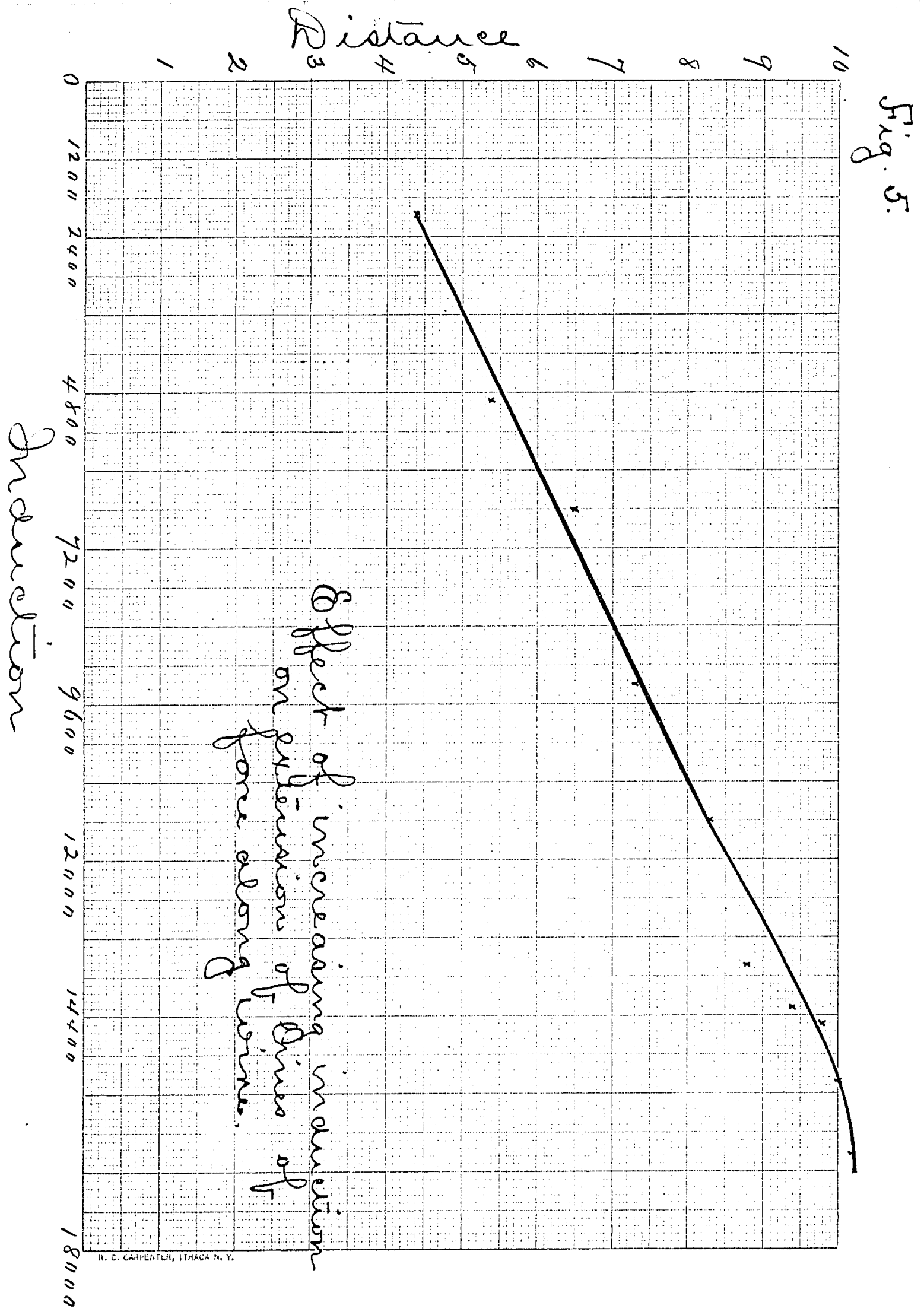




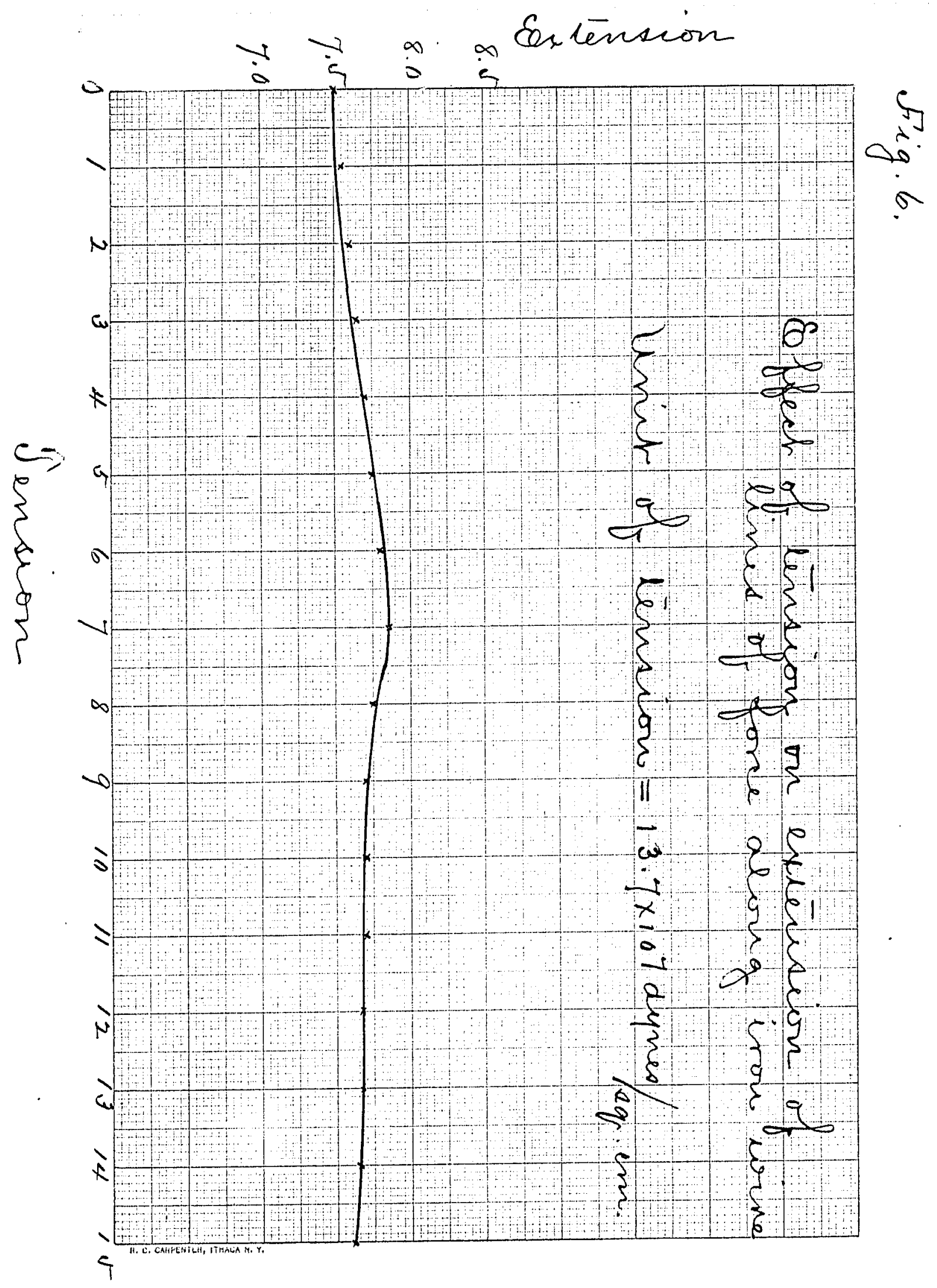




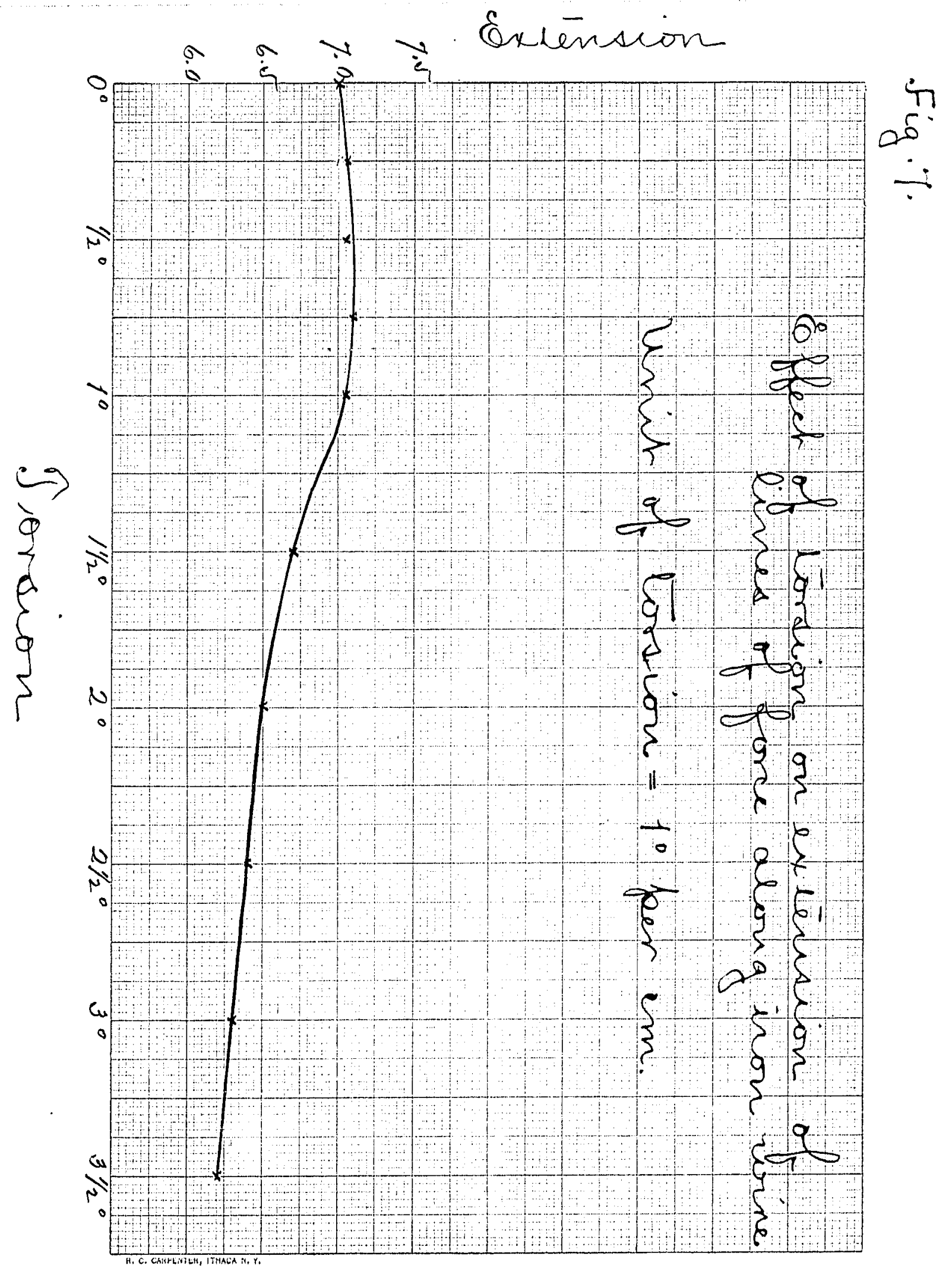




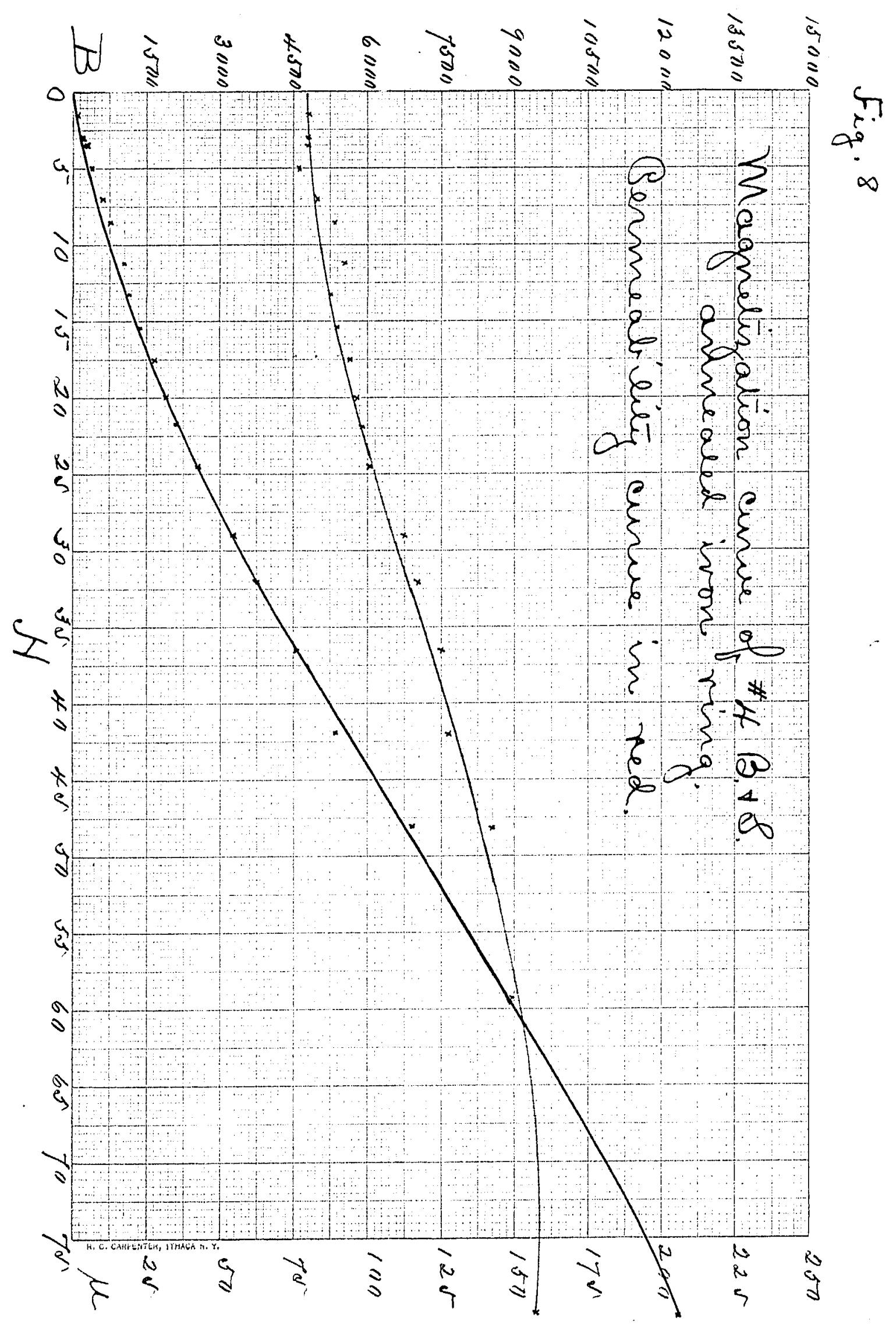




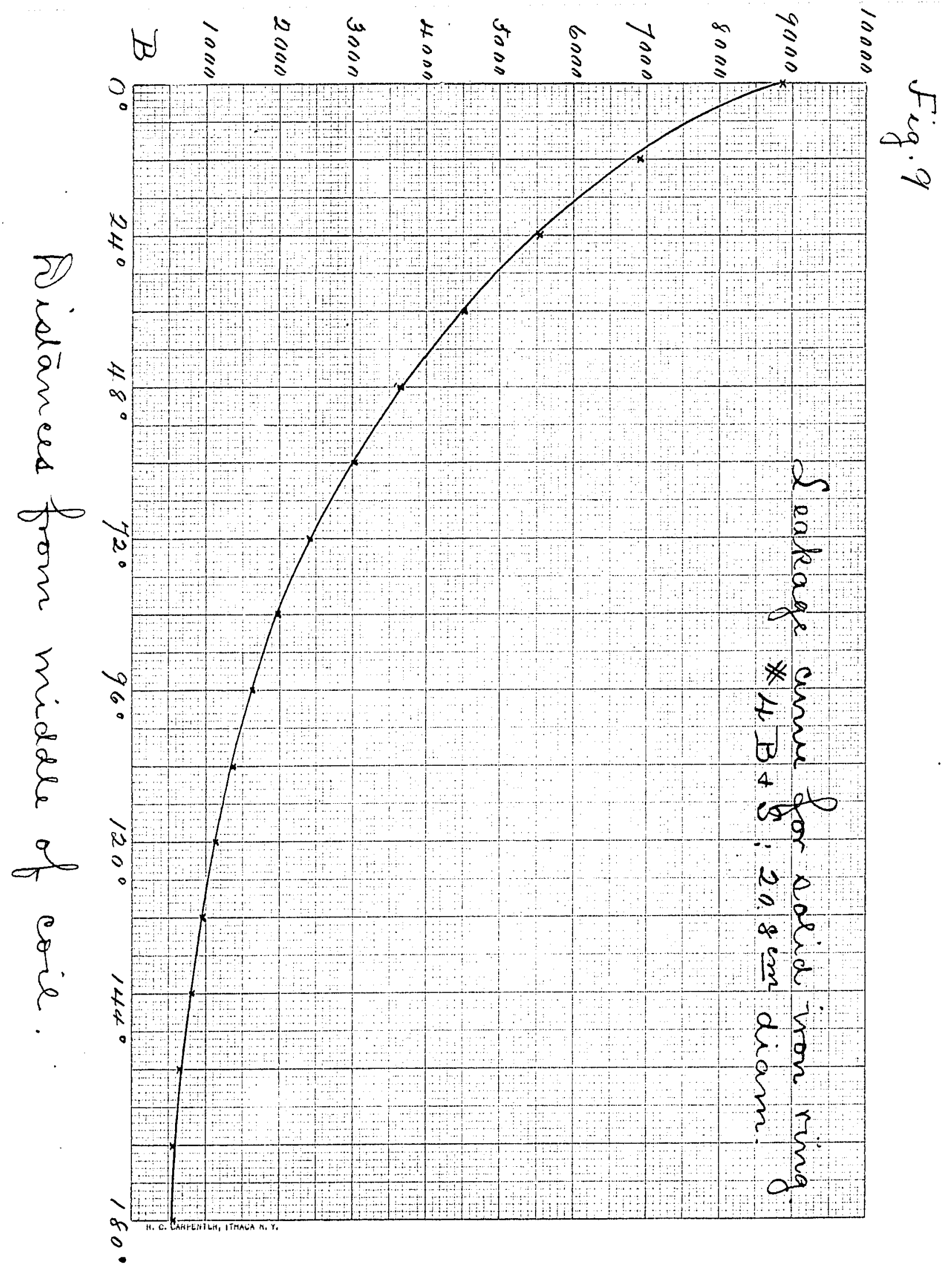




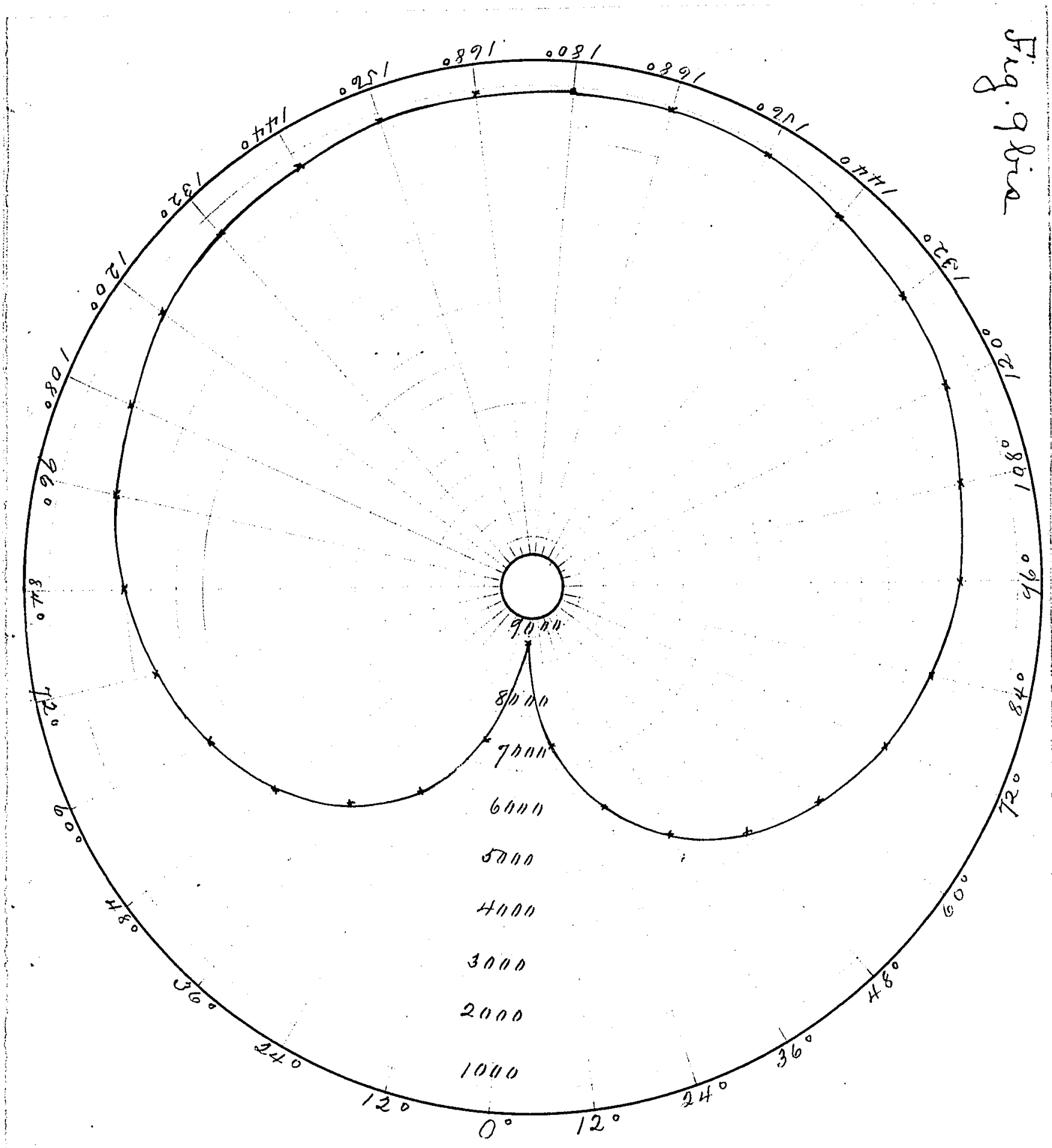

Leakage of Magnetic Sines of Force around bincular Ring 


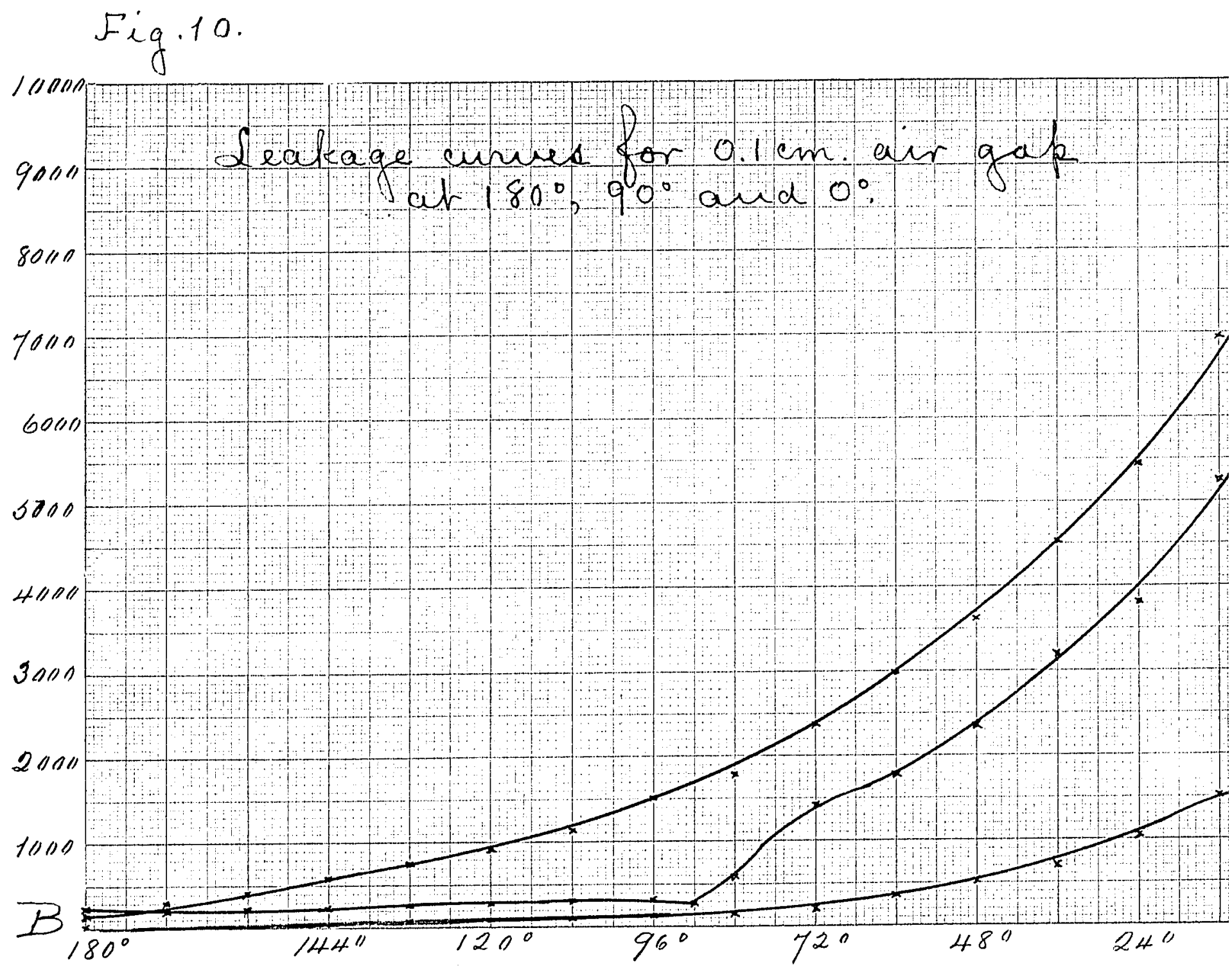

Nistarces from midale of coil 
$$
\text { (1) }
$$

. .
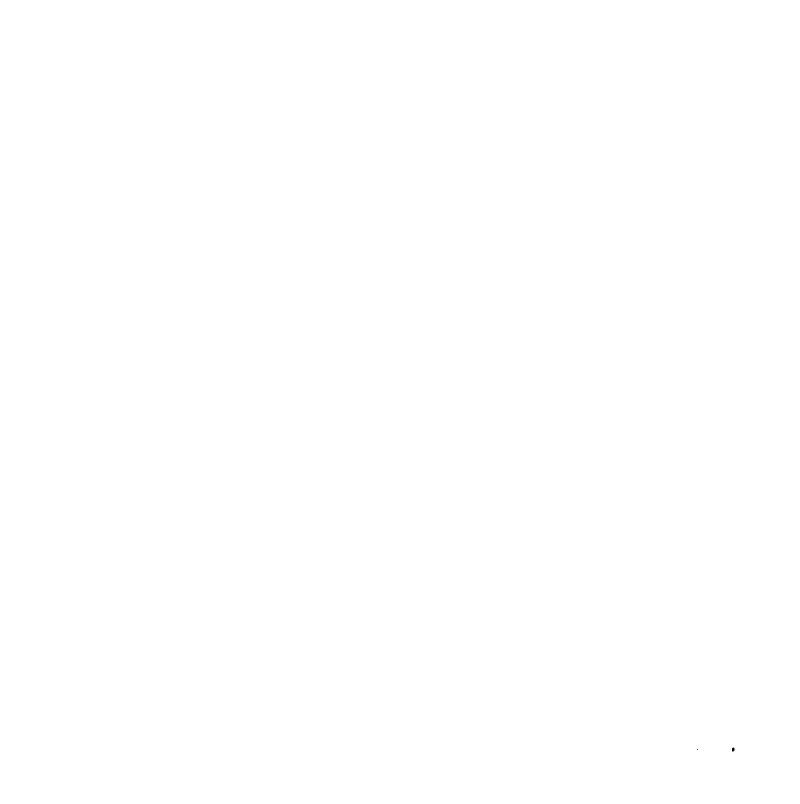

.

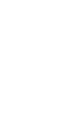
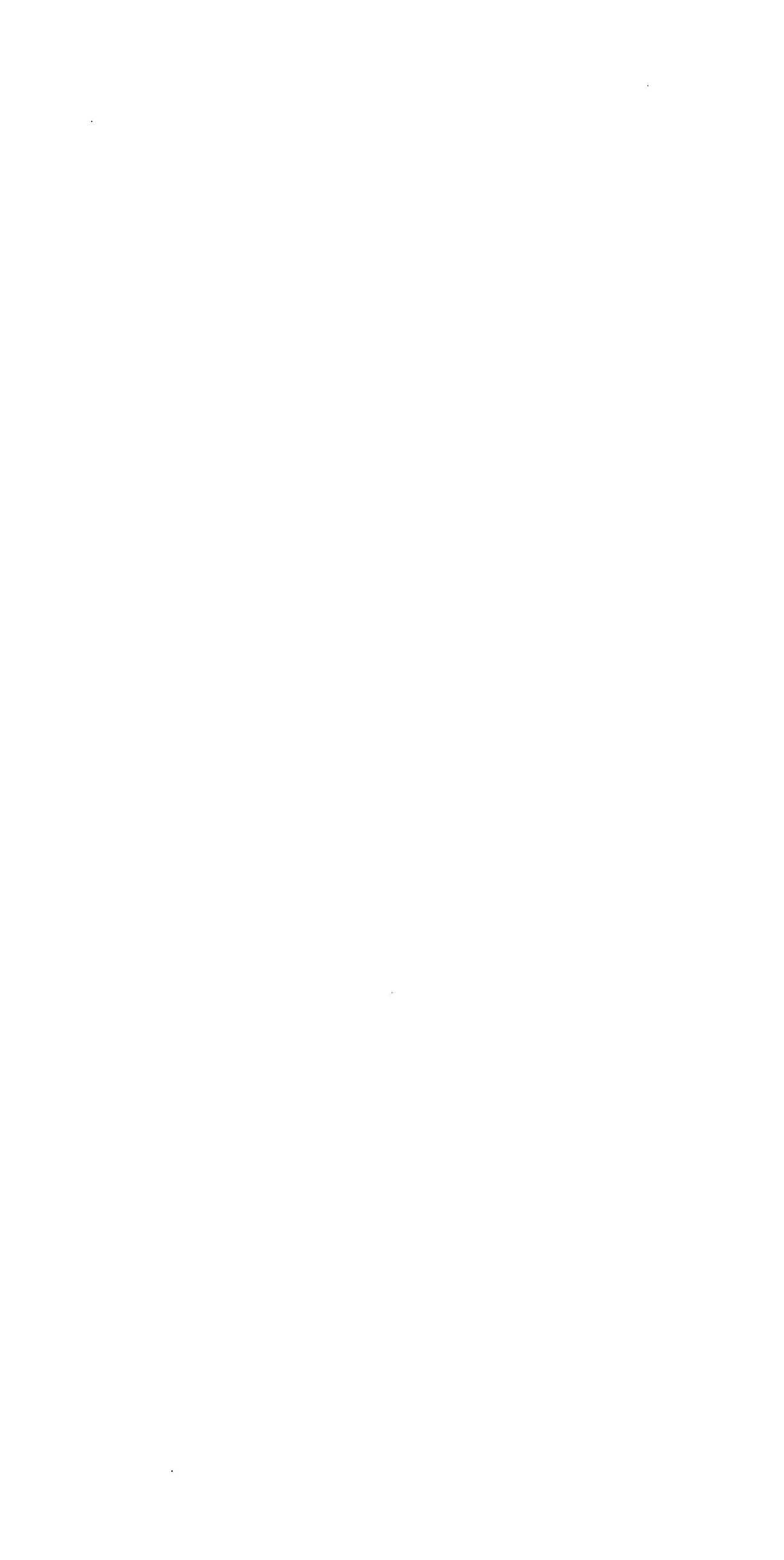


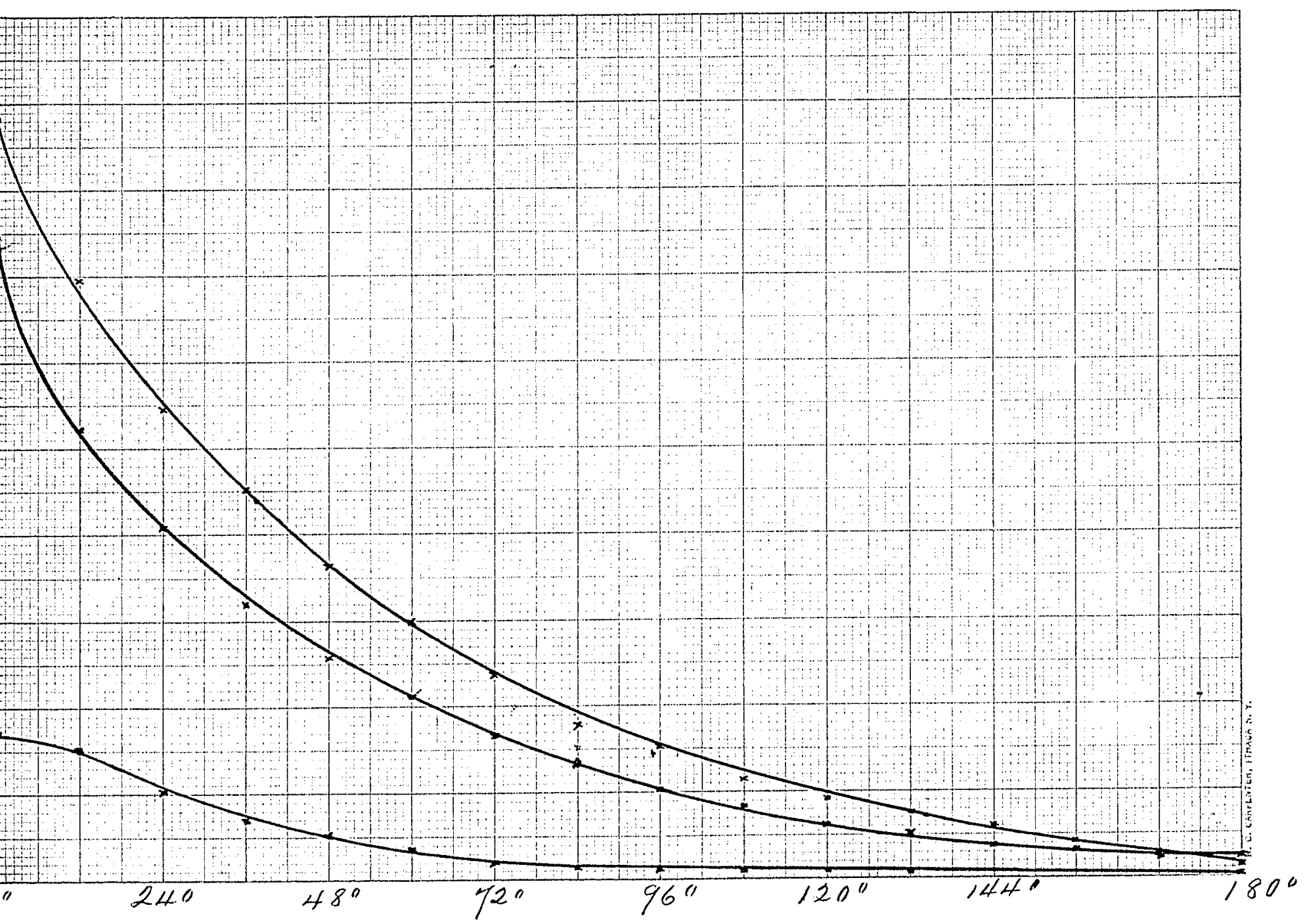



fig. 10 bis

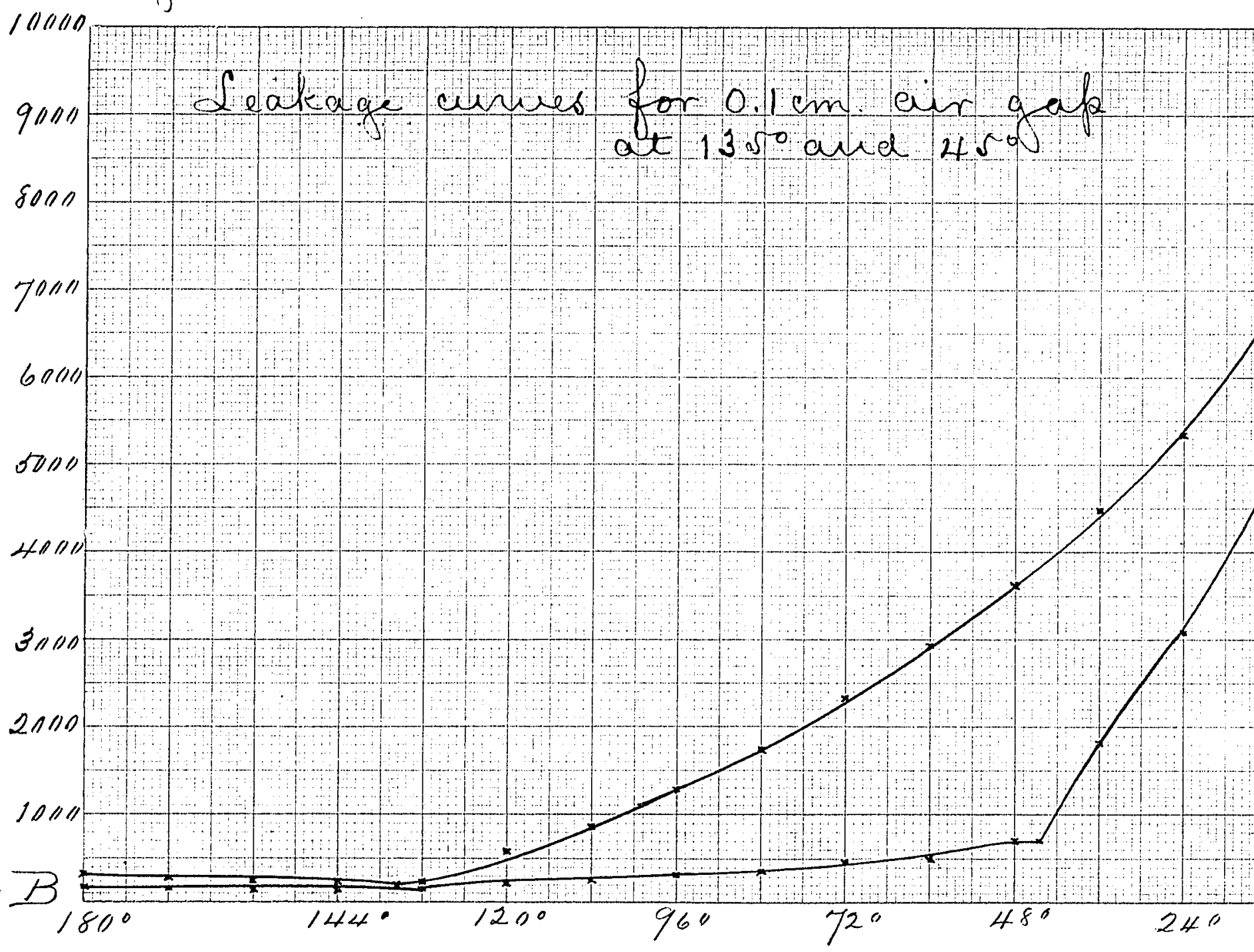

Distances from middle of ar ie.

i 


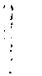

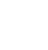




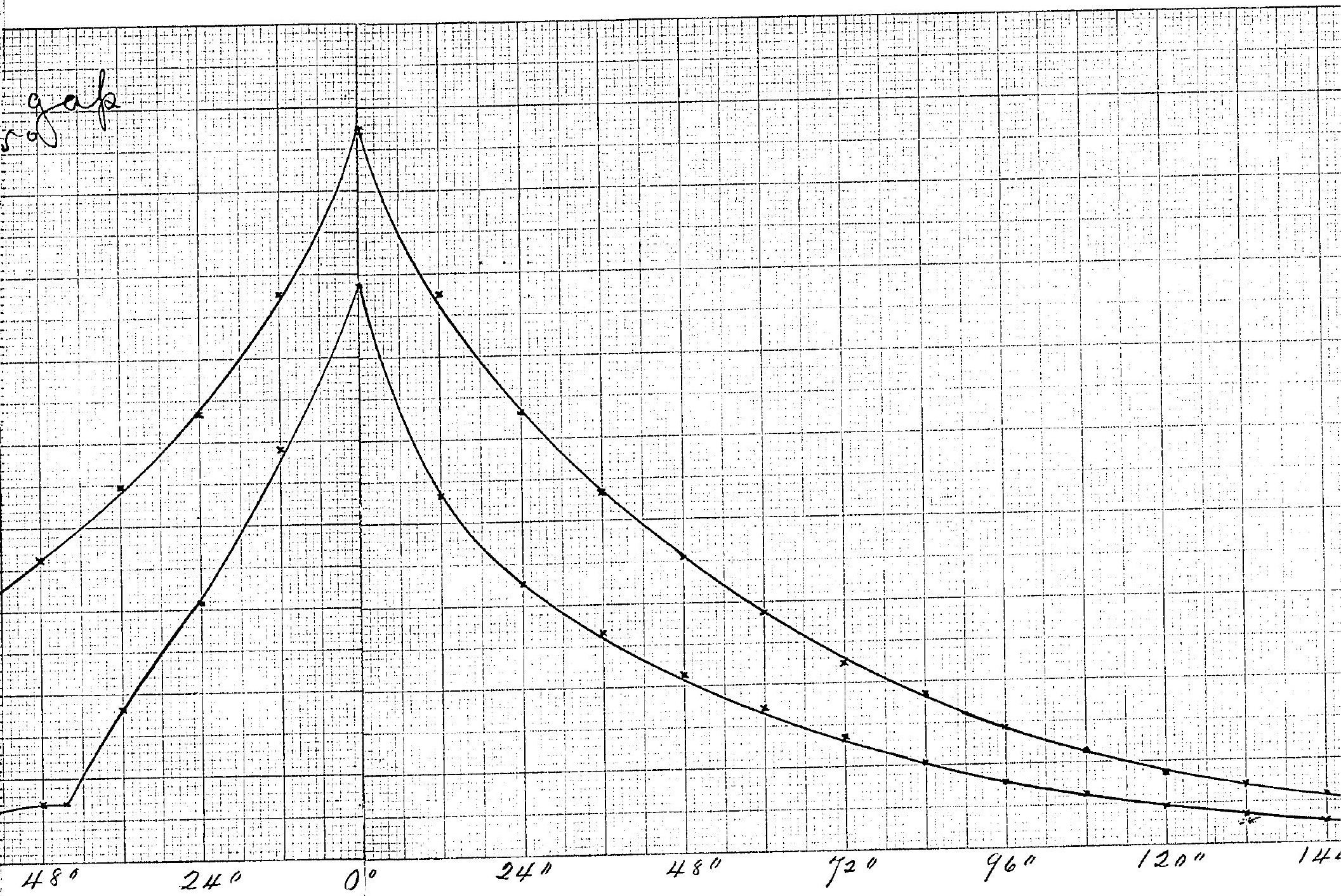





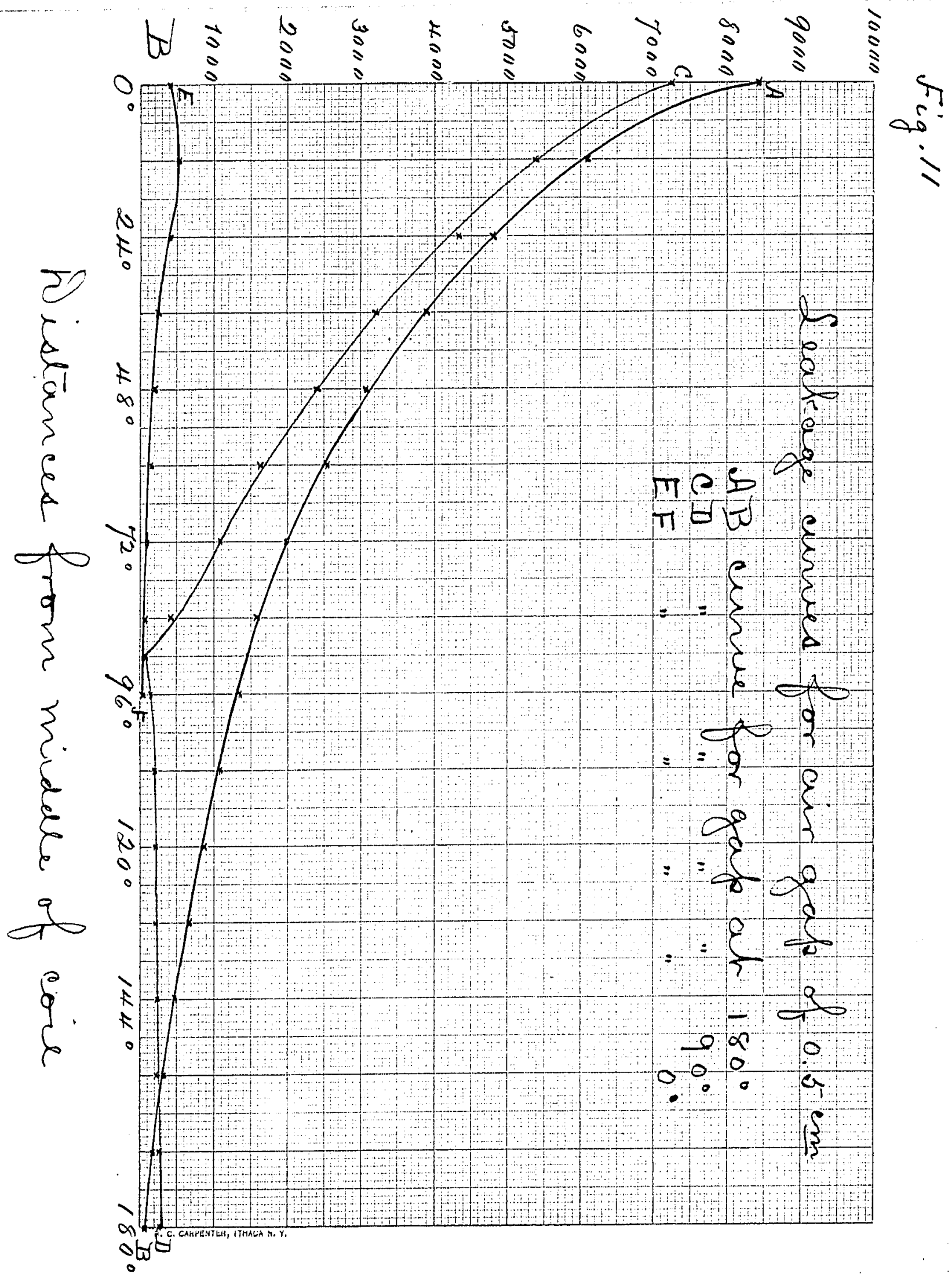




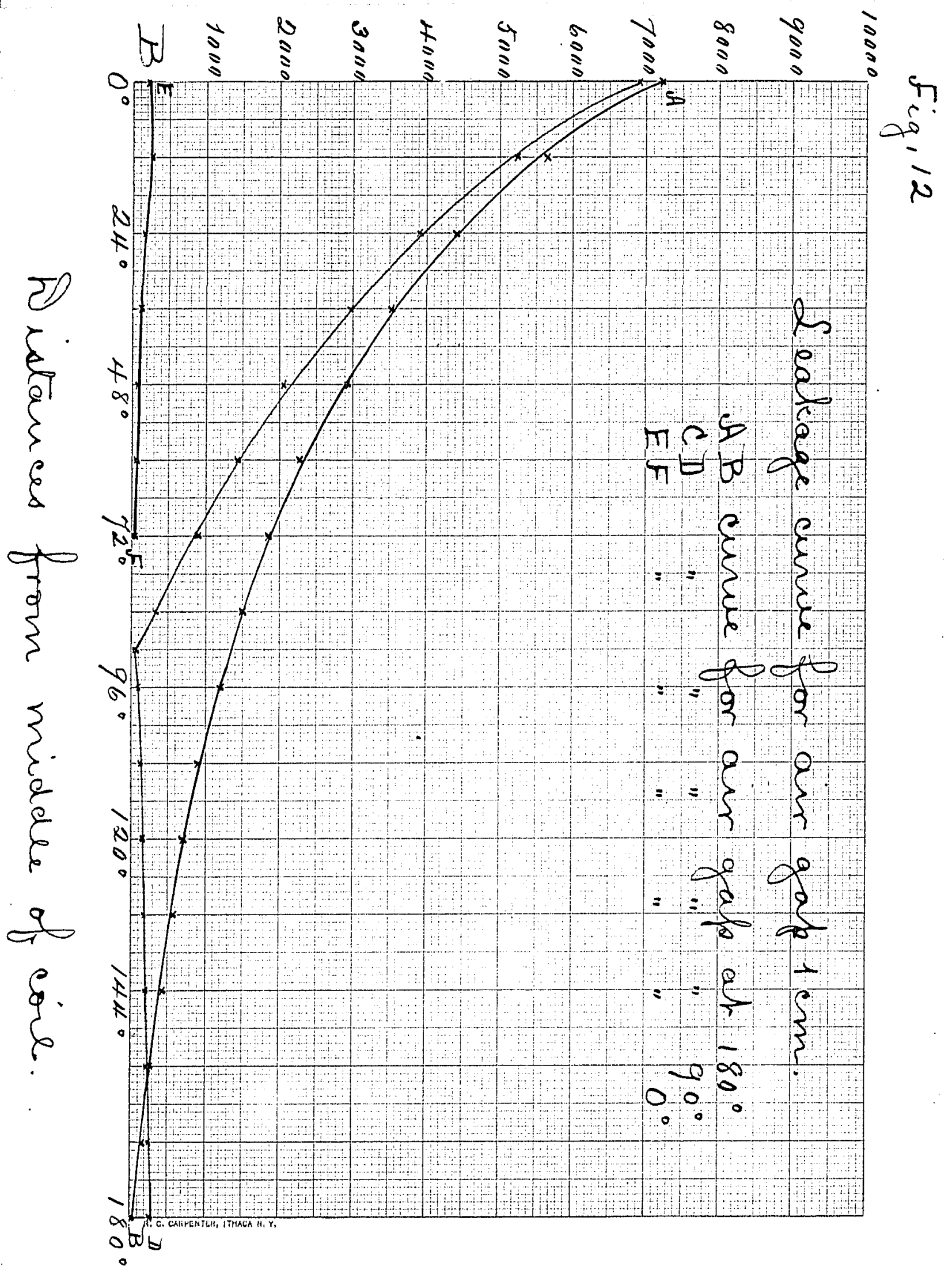

